\title{
Study on Stability of Shield Tunnel Excavation Face in Soil-Rock Composite Stratum
}

\author{
Hongtao Sui $\mathbb{D}^{D}$, Chao Ma, Chunquan Dai $\mathbb{D}$, and Tingzhi Yang \\ School of Civil Engineering and Architecture, Shandong University of Science and Technology, Qingdao 266590, Shandong, China \\ Correspondence should be addressed to Hongtao Sui; shttriumph@126.com
}

Received 1 February 2021; Revised 22 February 2021; Accepted 10 March 2021; Published 30 March 2021

Academic Editor: Qian Zhang

Copyright (C) 2021 Hongtao Sui et al. This is an open access article distributed under the Creative Commons Attribution License, which permits unrestricted use, distribution, and reproduction in any medium, provided the original work is properly cited.

\begin{abstract}
In order to study the instability mode of shield excavation face in soil-rock composite stratum and determine the ultimate support pressure of excavation face, this paper selects two typical soil-rock composite strata and uses three-dimensional finite element software to study the failure development process of shield excavation face. Based on the principle of limit equilibrium, a calculation model of limit support pressure for soil-rock composite stratum is proposed and applied to practical engineering. It is found that the shape of "unloading loosening zone" is mainly determined by the properties of upper soil and the properties of lower rock mainly determine the scope and shape of "sliding instability zone." With the increase of soil proportion coefficient, the ultimate bearing capacity increases nonlinearly and the growth rate decreases gradually. At the same time, the influence of overlying Earth pressure and soil cohesion cannot be ignored.
\end{abstract}

\section{Introduction}

In the construction of urban rail transit, the instability of stratum disturbance and the complexity and sensitivity of surrounding environment are the objective reality faced by builders. Especially, when tunneling in a soil-rock composite formation, the engineering properties of the upper soil layer and the lower rock formation are quite different, such as deformation characteristics and strength characteristics, so that the ground displacement and deformation caused by the shield tunneling in the soil-rock composite formation are relatively large. Complicated, the difficulty of controlling the support pressure of the excavation surface is greatly increased compared with that of a homogeneous layer, and the rock and soil are prone to instability and damage due to insufficient support of the excavation surface, which has a great impact on the project [1-5]. Therefore, it is of great significance to deeply study the deformation and failure mechanism of the excavation face caused by the shield tunneling in the soil-rock composite stratum and to explore the ultimate support pressure of the shield tunneling in the soil-rock composite stratum.

Up to now, many scholars at home and abroad have carried out a lot of research on the stability of the excavation face and the determination of the ultimate support pressure of the excavation face of shield tunnel through the combination of numerical simulation and theoretical derivation [6-10]. In 1961, Horn [11] first proposed the wedge model of shield excavation face, which is mainly composed of the wedge in front of the excavation face and the prism above the excavation face. This study lays a foundation for the improvement of the subsequent three-dimensional wedge analysis model. Then, based on the silo model proposed by Horn and Janeseez and Steiner [12], Anagnostou and Kvoarl [13] considered the effect of horizontal soil arch, analyzed the influence relationship between the excavation face ultimate support force and tunnel diameter and water level height and soil parameters, and further established an improved three-dimensional wedge calculation model. The calculation results are closer to the model test results. 
Considering the actual shield working conditions, Liu [14] successfully extended the three-dimensional wedge calculation model of shield tunnel excavation face stability to composite stratum. Broere et al. $[15,16]$ extended Terzaghi loose Earth pressure formula to layered soil and studied the influence of soil heterogeneity on slip angle and minimum support pressure. Shahmoradi et al. [17] calculated the ultimate support pressure of the excavation face of the water conveyance tunnel considering the depth of the tunnel and the stratification of the stratum. In order to reduce the construction risk of underground engineering, Hernandez et al. [18] used analytical methods to evaluate the support pressure of different tunnel covers. Zhang et al. [19, 20] modified the traditional wedge calculation model considering the great difference of instability failure mode between the clay layer and sand layer. However, according to the existing research and analysis, the systematic research on the stability analysis of shield excavation face in soil-rock composite stratum is rarely involved. The evolution mechanism of instability caused by shield tunneling in soilrock composite stratum is not clear, and the applicability of the calculation method of tunnel overburden Earth pressure to this kind of stratum needs to be further studied, and it cannot accurately provide theoretical support for the setting of shield construction parameters.

Based on the shield construction experience and previous research results and combined with the existing shield construction conditions, this paper selects two typical soilrock composite strata and uses the three-dimensional finite element numerical simulation program to systematically study the development process of instability and failure of shield excavation face in soil-rock composite strata and the relationship between excavation face support force and displacement. Based on the numerical simulation results, the analytical model of ultimate support pressure of shield excavation face in soil-rock composite stratum is deduced, and the Terzaghi loose Earth pressure formula is improved to be applied to the calculation model of wedge in soil-rock composite stratum. The reliability and accuracy of the proposed method are verified by comparing the calculation results of the soil-rock composite formation wedge model with those of numerical calculation. Based on the R3 line of Jinan metro, the paper makes an example analysis and analyzes the sensitivity of several main parameters affecting the ultimate support force of shield excavation face, so as to further understand the calculation model method of soilrock composite stratum wedge. Relevant conclusions can provide theoretical support for rapid and safe shield tunneling in soil-rock composite stratum.

\section{Analysis of Deformation and Failure of Excavation Face}

2.1. Numerical Model and Calculation Process. In order to simplify the calculation, half of the symmetry of the shield tunnel is used for analysis, without considering the actual advancement process of the shield tunnel. The $X$ direction of the model is the shield tunneling direction, with a length of $80 \mathrm{~m}$; the $Y$ direction is perpendicular to the tunneling direction, with a length of $40 \mathrm{~m}$; the $Z$ direction is vertical, with a length of $30 \mathrm{~m}$ [21]. The ABAQUS finite element meshing is shown in Figure 1, and the element properties use eight-node linear hexahedral elements. The shield excavation diameter $D$ is $6.4 \mathrm{~m}$, and the shield buried depth $\mathrm{C}$ is $6.4 \mathrm{~m}$. There are 64169 units and 70512 nodes in the model. The purpose of numerical simulation in this section is to reveal the active failure mode of shield excavation face in soil-rock composite stratum and analyze the influence of different soil-rock composite stratum on the ultimate support pressure of active failure of excavation face and the relationship between support pressure and displacement of excavation face.

For the convenience of description, this paper introduces the concept of support stress ratio proposed by Qin [22]:

$$
\lambda=\frac{\sigma_{s}}{\sigma_{0}},
$$

where $\lambda$ is the support stress ratio, $\sigma_{s}$ is the support stress at the center of excavation face, and $\sigma_{0}$ is the original static Earth pressure at the center of excavation face.

It is assumed that the interface of soil-rock composite stratum is in the center of the shield excavation face, and it is evenly divided up and down. The ABAQUS simulation process of active failure of shield excavation face in soil-rock composite stratum is as follows:

(1) Assign stratum parameters and other model parameters suitable for the actual project.

(2) Establish the original soil-rock composite stratum model according to the selected parameters, except for the free surface of the ground surface, and impose displacement constraint boundary conditions around it.

(3) Equilibrium initial ground stress field.

(4) Excavate the tunnel to a certain distance at one time and stop the excavation. At the same time, a normal displacement constraint boundary condition is applied to the tunnel, and a trapezoidal supporting force equal to the static Earth pressure of the original stratum is applied on the tunnel excavation surface, and the model is iterated to reach a balanced state [21].

(5) Set up observation points that can reflect stratum changes, as shown in Figure 2. The support pressure of the excavation face gradually decreases at a slow speed, and the displacement, stress, and plastic zone of the rock and soil in front of the excavation face in each analysis step are tracked and recorded.

(6) When the support force of the excavation face reaches the active limit support force, the displacement of the node in front of the excavation face develops rapidly under the condition of small reduction of support pressure. It is considered that the excavation face is in active instability, and the support pressure of the excavation face at this time is 


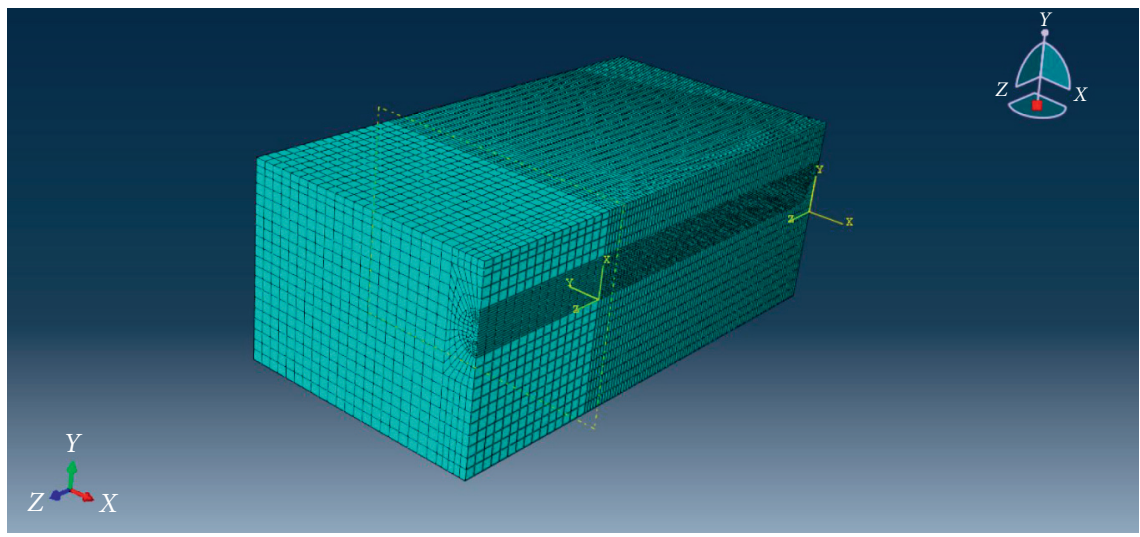

FIgURE 1: Gridding graph.

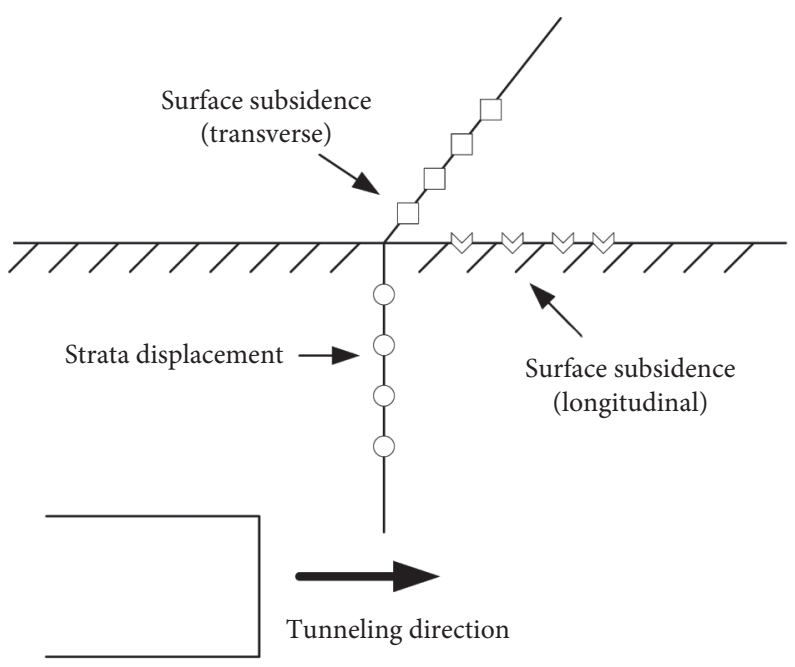

Figure 2: Schematic diagram of observation points.

the ultimate minimum support pressure, and the calculation can be terminated.

2.2. Calculation Conditions and Soil Parameters. According to the actual shield tunnel construction conditions, such as Jinan metro, Changchun Metro, and Guangzhou Metro, two different soil-rock composite strata are selected to simulate under the condition of $C / D=1.0$, and there are two excavation schemes. In this paper, the calculation of geotechnical materials follows Mohr-Coulomb criterion, and the excavation scheme and parameters are shown in Table 1.

\subsection{Analysis of Calculation Results}

2.3.1. Result Analysis of Scheme 1. Sand and clay are two typical strata often encountered in shield engineering. However, the physical and mechanical properties of clay and sand are quite different, which mainly depends on the differences in the structure, constitution, and properties of the soil particle units that make up the clay [23]. Therefore, shield construction in the clay layer is different from that in the sand layer in the stability of excavation face. When the clay layer and the moderately weathered limestone or strongly weathered mudstone layer form a composite stratum if the support pressure of the excavation face is not set properly, the deformation of the rock and soil in front of the excavation face is difficult to control, and the tunnel face instability accidents occur from time to time. Therefore, it is necessary to carry out the research on the stability of the shield excavation face in this composite stratum.

(1) Active Failure Mode. The soil displacement in front of the shield excavation face corresponding to the three analysis steps is shown in Figure 3.

It can be clearly seen from the figure that, with the decrease of support stress ratio $\lambda$, the clay layer in front of the shield tunnel face deforms and gradually expands to the surface, and the scope gradually increases; however, the moderately weathered limestone layer does not show obvious deformation due to its high strength. The biggest 
TABLE 1: Excavation scheme and parameter value table.

\begin{tabular}{|c|c|c|c|c|c|c|c|}
\hline $\begin{array}{l}\text { Scheme } \\
\text { no. }\end{array}$ & Type & Name & $\begin{array}{l}\text { Density } \\
(\mathrm{kg} / \mathrm{m} 3)\end{array}$ & $\begin{array}{l}\text { Elastic modulus } \\
(\mathrm{MPa})\end{array}$ & $\begin{array}{l}\text { Poisson's } \\
\text { ratio }\end{array}$ & $\begin{array}{l}\text { Cohesion } \\
(\mathrm{kPa})\end{array}$ & $\begin{array}{l}\text { Internal friction } \\
\text { angle }\left(^{\circ}\right)\end{array}$ \\
\hline \multirow[b]{2}{*}{1} & Soil mass & Clay & 1970 & 5 & 0.20 & 10 & 18 \\
\hline & $\begin{array}{l}\text { Rock } \\
\text { mass }\end{array}$ & $\begin{array}{l}\text { Moderately weathered } \\
\text { limestone }\end{array}$ & 2500 & 2000 & 0.21 & 100 & 30 \\
\hline \multirow[b]{2}{*}{2} & Soil mass & Clay & 1970 & 5 & 0.20 & 10 & 18 \\
\hline & $\begin{array}{l}\text { Rock } \\
\text { mass }\end{array}$ & $\begin{array}{l}\text { Strongly weathered } \\
\text { mudstone }\end{array}$ & 1920 & 40 & 0.26 & 37.3 & 25.6 \\
\hline
\end{tabular}

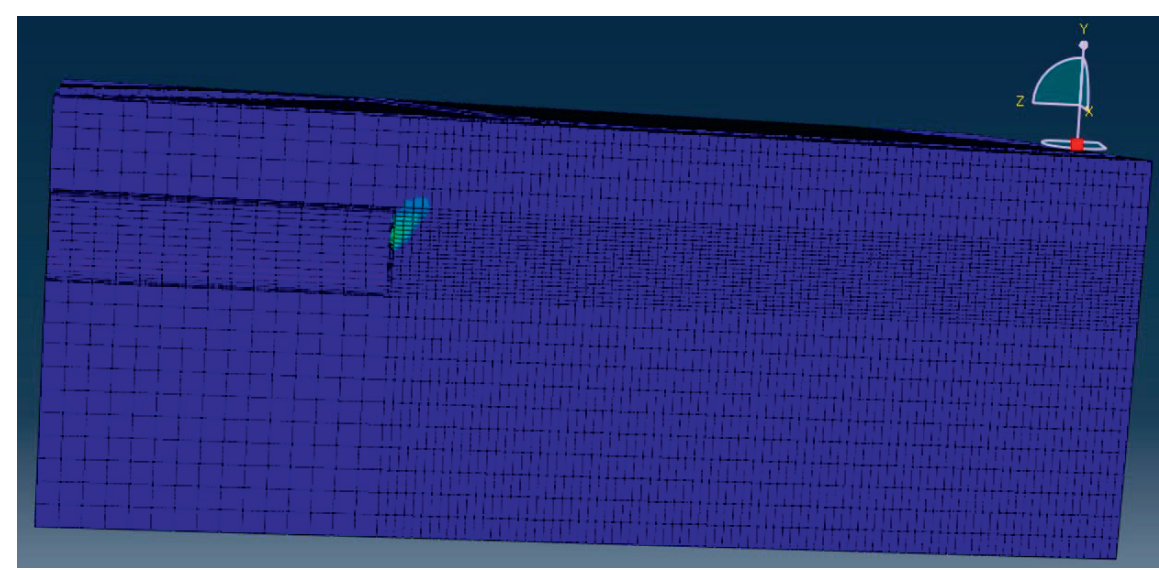

(a)

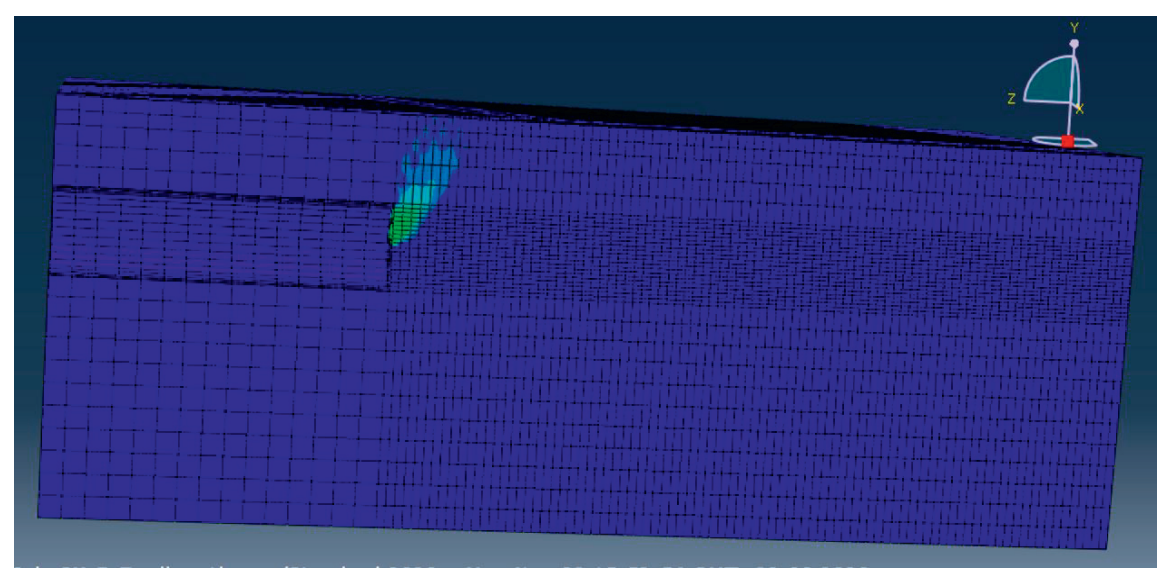

(b)

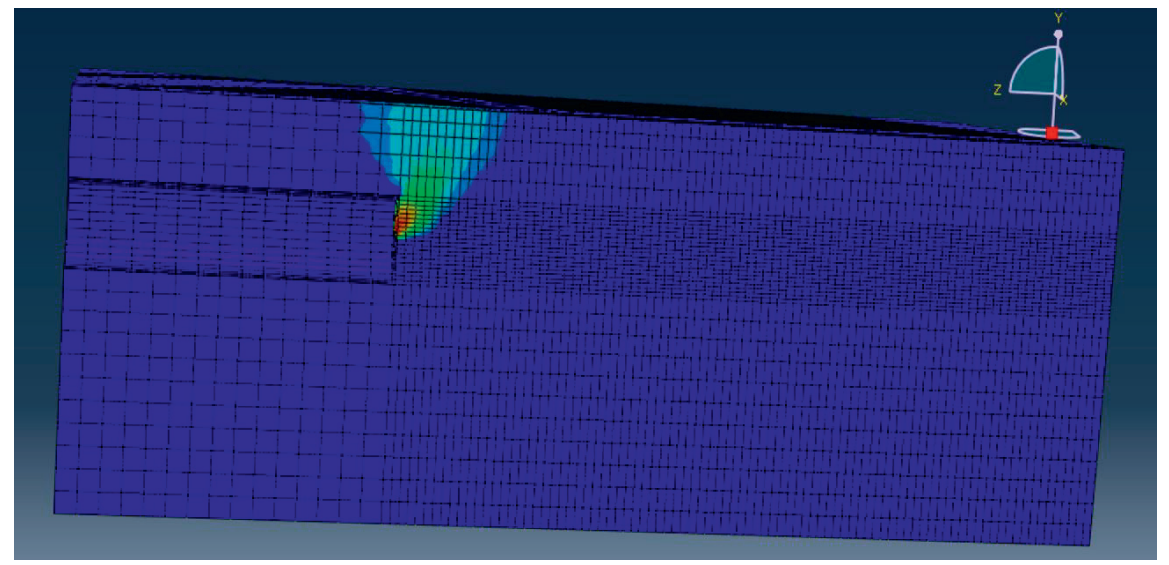

(c)

Figure 3: Displacement isosurface map. (a) Displacement nephogram of displacement at $\lambda=0.8$. (b) Displacement nephogram of displacement at $\lambda=0.4$. (c) Displacement nephogram of displacement at $\lambda=0$. 
difference from the sandy soil layer is that its damage shape is obviously larger than the "chimney shape," showing an "inverted trapezoid" with a wide top and a narrow bottom.

(2) Ultimate Support Pressure of Active Failure. According to the previous analysis, when the shield tunneling in the claymedium weathered limestone composite stratum, the instability of the excavation face due to insufficient support pressure starts from the clay layer and gradually develops to the surface. Therefore, the center point of the clay layer on the tunnel face is selected as the reference point to analyze the load-displacement curve of tunnel face. The history curve is shown in Figure 4, where $\lambda_{\mathrm{s}}$ represents the support stress ratio at the center point of the upper clay layer and $S_{\mathrm{s}}$ is the displacement of the center point of the upper clay layer.

It can be seen from Figure 4 that the whole load-displacement curve can be divided into three stages: in the first stage, the displacement of the excavation face increases slowly with the decrease of the support pressure; in the second stage, the displacement of the excavation face increases significantly; at this time, the support pressure of the excavation face is close to the limit support pressure; in the third stage, the displacement of the excavation face increases sharply and enters the failure stage of the support pressure; at this time, the support pressure is the limit support pressure of the excavation face, which is about $10 \%$ of the static Earth pressure of the original formation.

\subsubsection{Result Analysis of Scheme 2}

(1) Active Failure Mode. In this scheme, the clay-strongly weathered mudstone composite stratum is used as the stratum condition, and the displacement isosurface map (side view) of rock and soil mass in front of the excavation face when the excavation face is finally unstable is shown in Figure 5.

It can be seen from Figure 5 that when the shield tunneling in the clay-strongly weathered mudstone composite stratum and when the soil bunker pressure provided by the shield machine is not enough to maintain the stability of the rock and soil in front of the tunnel face, the rock and soil in front of the tunnel face will undergo obvious deformation and eventually instability, and the instability area will spread to the surface when the burial depth ratio $\mathrm{Cl}$ $D=1.0$.

(2) Ultimate Support Pressure of Active Failure. The relationship between the horizontal displacement at $0.32 \mathrm{~m}$ above the tunnel center point and the support stress ratio is shown in Figure 6.

It can be seen from Figure 6 that the whole load-displacement curve can also be divided into three stages: in the first stage, with the decrease of support pressure, the displacement of the excavation face increases slowly; in the second stage, the displacement of the excavation face increases faster; at this time, the support pressure of the excavation face is close to the limit support pressure; in the third stage, the displacement of the excavation face increases

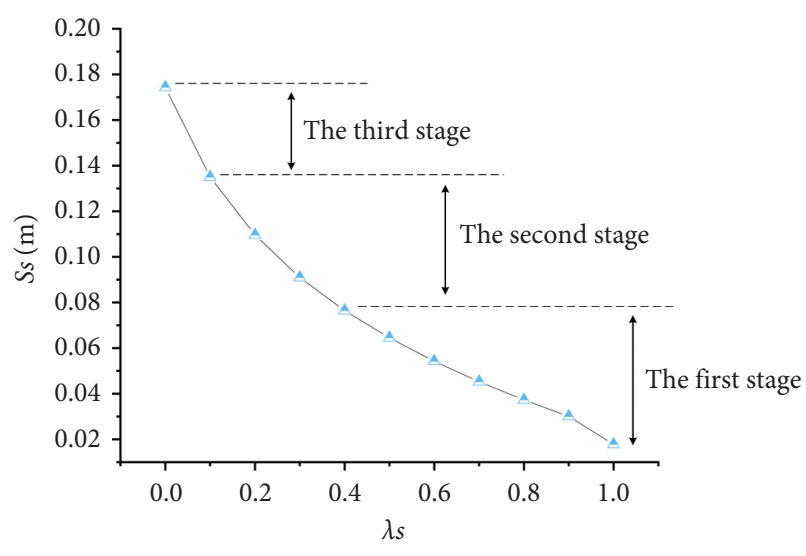

Figure 4: Load-displacement curve of the face.

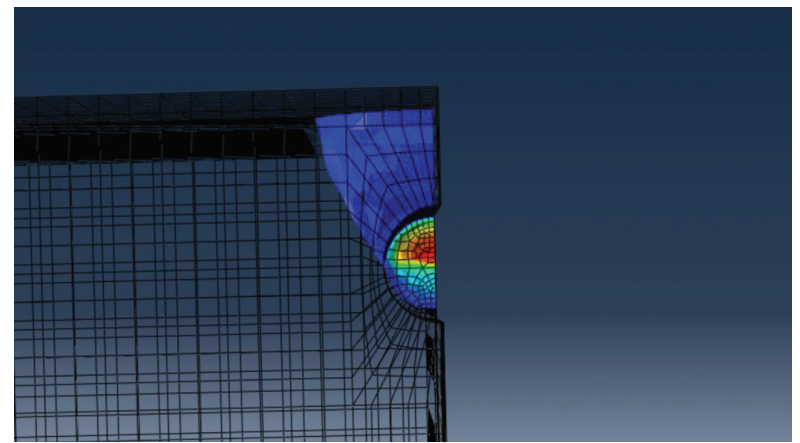

FIGURE 5: Contour map of final instability of the face.

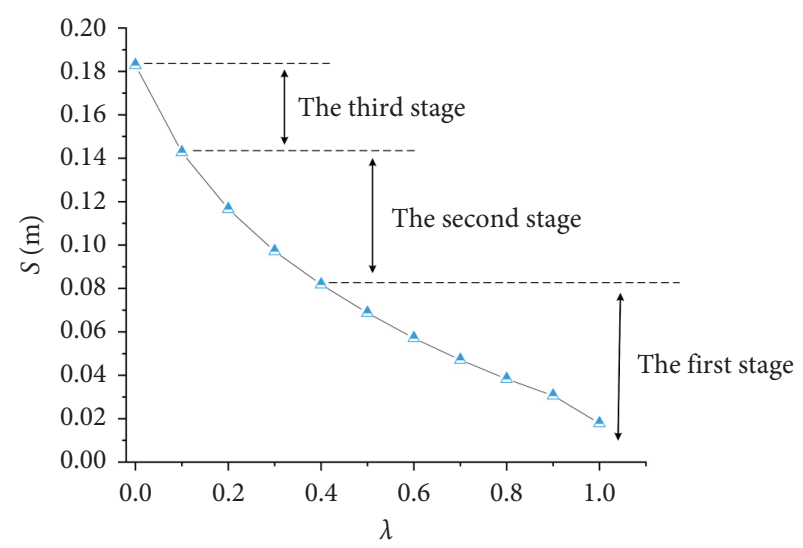

Figure 6: Load-displacement curve of the face.

sharply, and it enters into the failure stage of support pressure, at this time the ultimate support pressure of the excavation face is about $10 \%$ of the static Earth pressure of the original formation.

\section{Theoretical Analysis of Excavation Face Stability}

3.1. Discussion on Instability Mode of Excavation Face in SoilRock Composite Stratum. Throughout the past research, many scholars have carried out a series of research on the 
instability mode of single stratum [24], among which the sand soil layer and clay soil layer as typical stratum have been the research hotspot [25]. Figure 7 shows the instability failure mode of shield excavation face in the sand soil layer. With the large-scale development of underground space, the geological conditions encountered in shield construction are gradually complicated. People gradually realize that shield construction technology is closely related to geological characteristics, especially in soil-rock composite stratum. However, previous studies have paid too much attention to the "upper soft and lower hard" composite stratum $[6,14,26]$, but little attention to the influence of the upper and lower rock and soil properties on the instability model, and lack of systematic research on the soil-rock composite stratum. In this paper, the numerical simulation shows that when shield tunneling in soil-rock composite stratum, the instability mode of the excavation face is directly related to geological conditions due to insufficient support pressure. The shape of the loosening failure zone is determined by the properties of the upper soil layer, and the shape of the sliding instability zone is determined by the properties of the lower rock layer. When the upper soil layer is clay and the lower rock layer is moderately weathered limestone, with the gradual reduction of support pressure, the shape of sliding instability zone in front of the excavation face is similar to that of upper soft and lower hard strata, but the shape of the upper loose failure zone is no longer "chimney shape," but becomes "inverted trapezoid" with upper width and lower narrow; when the upper soil layer is clay and the lower rock layer is strongly weathered mudstone, with the gradual reduction of support pressure, the shape of the upper loose failure zone is similar to that of Scheme 1, showing an inverted trapezoid with wide upper and narrow lower, but the shape of the sliding instability zone in front of excavation is obviously different. Figure 8 shows the instability modes of the shield excavation face of two different soil-rock combinations obtained by the numerical simulation in this paper.

It can be seen from Figure 8 that, in the soil-rock composite stratum, the nature of the lower stratum mainly determines the shape of the sliding instability zone. When the firmness coefficient of the lower strata is large, the sliding instability area starts from the interface between the soil layer and the rock layer, showing a "local wedge;" when the firmness coefficient of the lower strata is small, the sliding instability area starts from the bottom of the shield, showing a "folded wedge." It can be seen that the instability form of the shield excavation face in soil-rock composite stratum is different from that in homogeneous stratum, which directly affects the calculation results of ultimate support force and is unfavorable to practical engineering. Therefore, the systematic study of soil-rock composite strata in this paper can

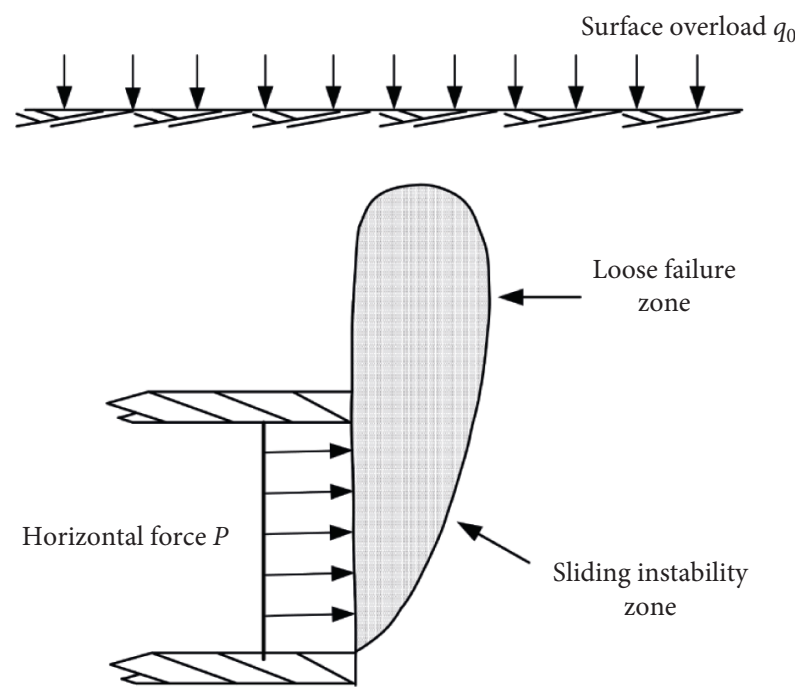

FIGURE 7: Instability and failure of the excavation face.

provide a necessary basis for the improvement of wedge model below and also provide a reference for the subsequent related research.

\subsection{Wedge Model of Soil-Rock Composite Stratum}

3.2.1. Establishment of Theoretical Model. Combined with the discussion in Section 3.1 of this paper, based on the limit equilibrium method, the traditional wedge calculation model [12] is improved, and a wedge calculation model suitable for soil-rock composite stratum is proposed, as shown in Figure 9. Among them, model 1 represents the "upper clay and lower hard" stratum represented by the moderately weathered limestone layer under the upper clay layer of scheme 1; model 2 represents the "upper clay and lower soft" stratum represented by the strongly weathered mudstone layer under the upper clay layer of Scheme 2. In fact, the shield profile is slightly larger than the square area of the wedge.

In order to simplify the derivation, the following assumptions are made for the wedge model of soil-rock composite stratum:

(1) Soil is a kind of isotropic rigid plastic material, which obeys Mohr-Coulomb strength theory

(2) When the upper stratum is clay, the loose failure area is inverted pyramid, as shown in Figure 10; when the lower stratum is moderately weathered limestone, the sliding instability area is wedge; when the lower stratum is strongly weathered mudstone, the sliding instability area is folded wedge

(3) The stress distribution on the top of wedge and inclined sliding surface is uniform 
$q_{0}$

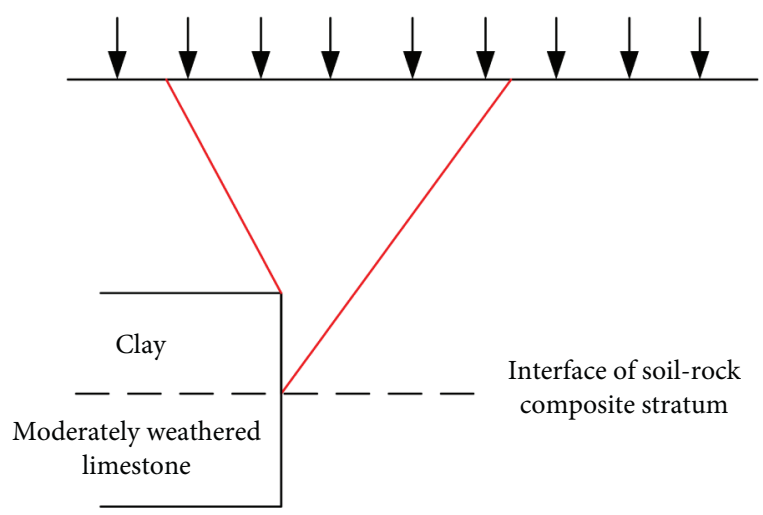

(a)

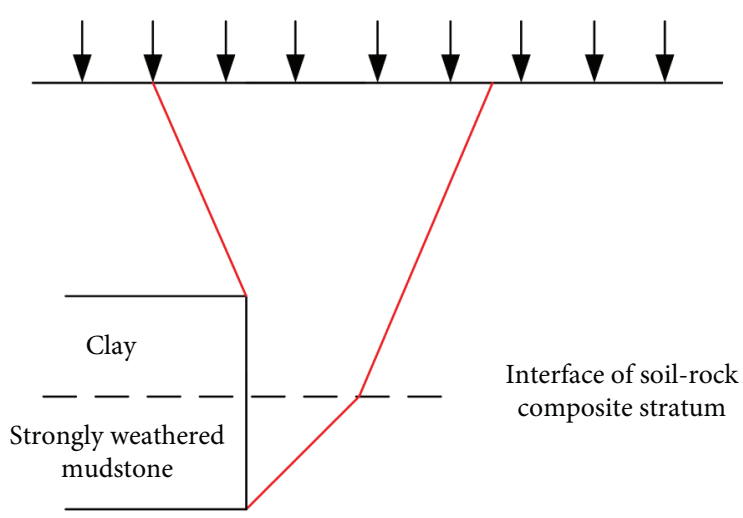

(b)

FIgURE 8: Instability mode of the excavation face in soil-rock composite stratum. (a) Option 1. (b) Option 2.
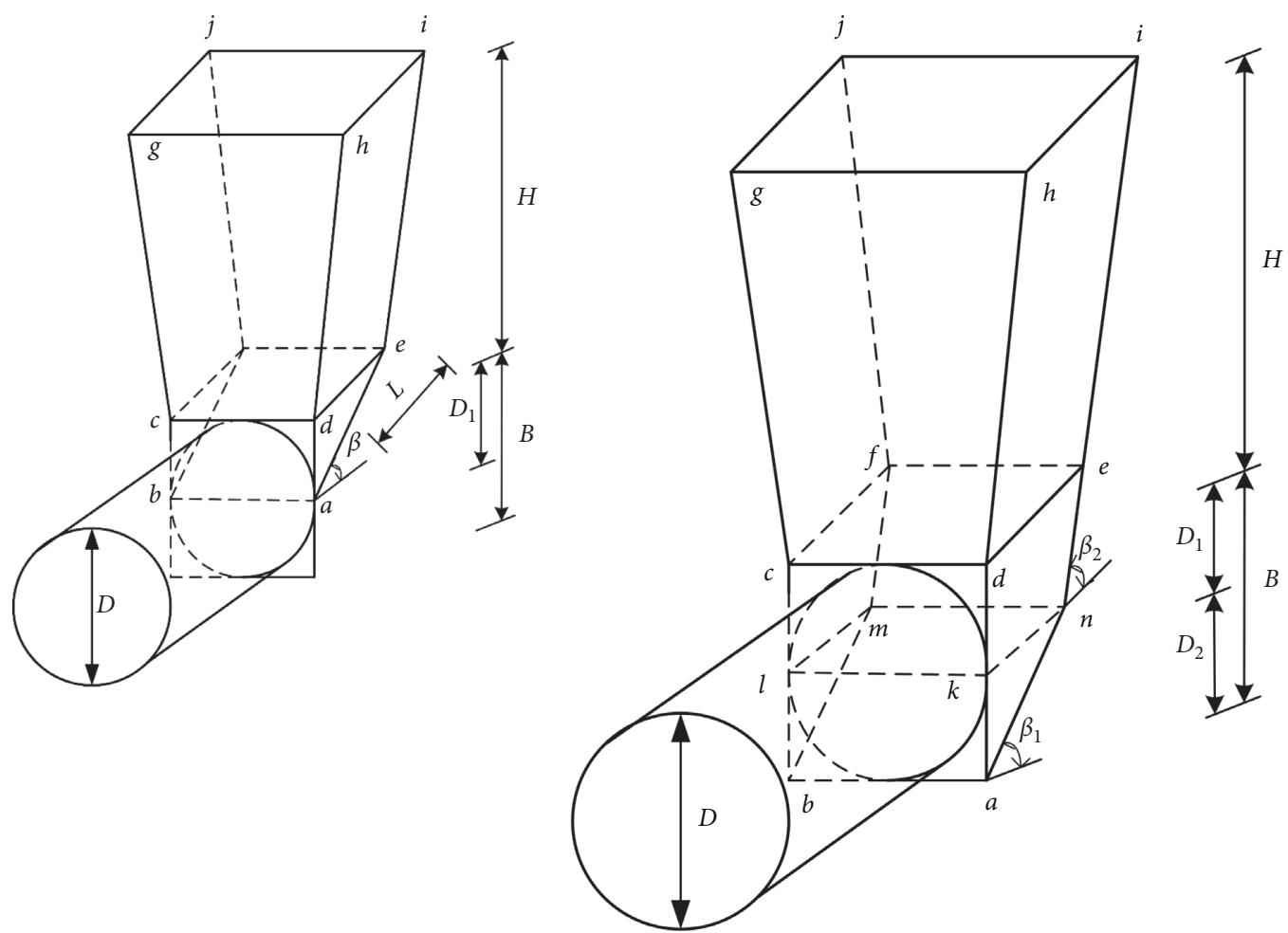

(a)

(b)

Figure 9: Wedge calculation model of soil-rock composite stratum. (a) Model 1. (b) Model 2.

(4) The vertical stress increases linearly with depth

(5) The influence of groundwater and its seepage is not considered

\subsubsection{Derivation of Ultimate Support Force of \\ Excavation Face}

(1) Force Analysis of Local Wedge. As shown in Figure 9, the sliding instability area in model 1 starts from the interface of soil-rock composite stratum, so it is called "local wedge" in this paper, and the stress of local wedge is shown in Figure 11. In the figure, $V$ is the resultant force of vertical overburden Earth pressure, $P_{s}$ is the total support pressure of upper soil excavation surface, $G$ is the self weight of local wedge, $N$ is the normal support force of soil on the slope of local wedge, $T_{1}$ is the friction force on the slope of local wedge, $T_{2}$ is the friction force on the side of local wedge, and $\beta$ is the angle between local wedge and horizontal plane.

Perform static balance analysis on the local wedge: 


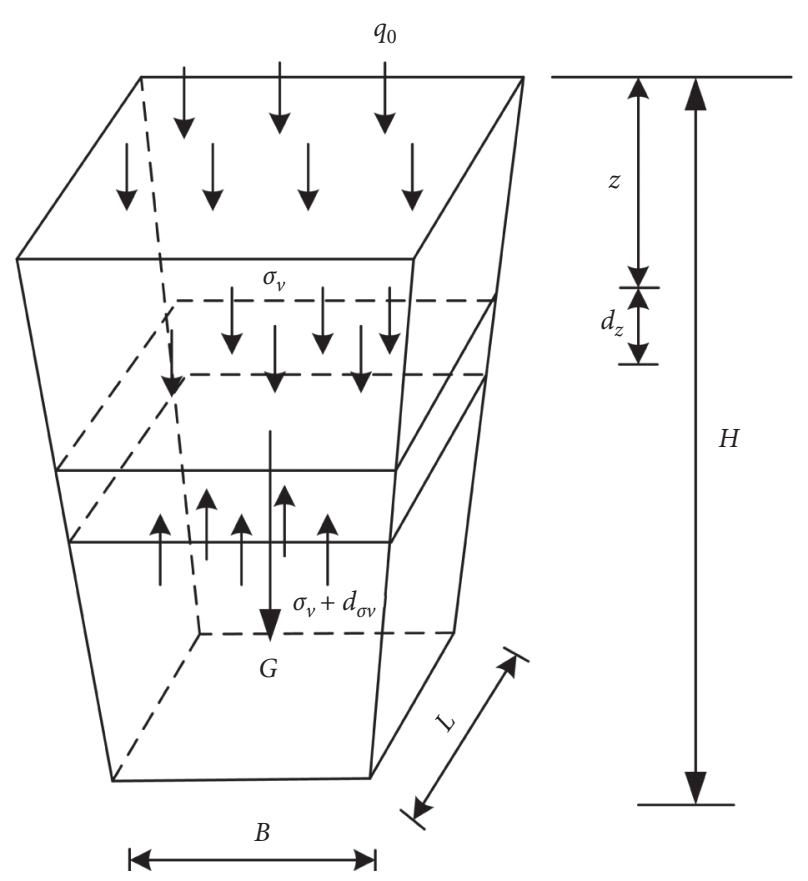

FIGURE 10: Calculation diagram of three-dimensional expansion of loose Earth pressure.

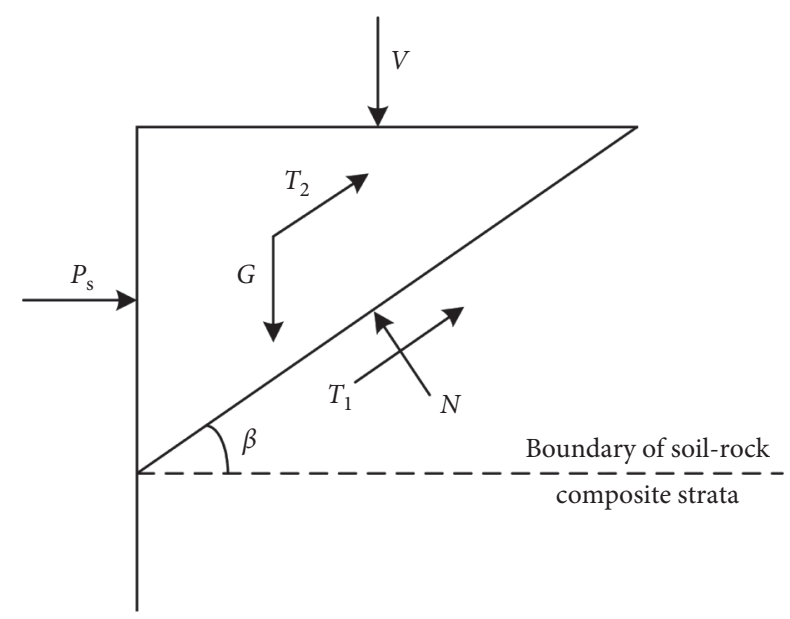

FIGURE 11: Stress diagram of local wedge.

$\sum F_{z}=0: V+G-T_{1} \sin \beta-2 T_{2} \sin \beta-N \cos \beta=0$,

$\sum F_{x}=0: P_{s}+T_{1} \cos \beta+2 T_{2} \cos \beta-N \sin \beta=0$.

According to Mohr-Coulomb criterion, the equation of critical state on the sliding surface of local wedge is as follows:

$$
\begin{aligned}
& \cdot T_{1}=S_{\text {anfe }}\left(\sigma \tan \varphi_{s}+c_{s}\right)=N \tan \varphi_{s}+\frac{c_{s} B D_{1}}{\sin \beta}, \\
& T_{2}=\frac{1}{2} D_{1} L\left(c_{s}+k_{0} \bar{\sigma}_{v} \tan \varphi_{s}\right),
\end{aligned}
$$

among,

$$
\begin{aligned}
& G=\frac{1}{2} D_{1} L B \gamma_{s}=\frac{\sqrt{\pi} D_{1}^{2} D \gamma_{s} \cot \beta}{4}, \\
& V=B L \sigma_{v}, \\
& \overline{\sigma_{v}}=\sigma_{v}+\frac{\gamma_{s} D_{1}}{3},
\end{aligned}
$$

where $B$ is the equivalent shield diameter [27], $c_{s}$ is the cohesive force of the upper soil layer of the excavation face, $D_{1}$ is the cohesive force of the upper soil layer of the excavation face, $L$ is the length of the top of the sliding block, $L=D_{1} \cot \beta, \varphi_{s}$ is the internal friction angle of the upper soil layer of the excavation face, $S_{\text {anfe }}$ is the area of anfe plane, $\sigma$ is the normal stress on the inclined plane of local wedge, $\overline{\sigma_{v}}$ is the vertical average stress of local wedge block, $\gamma_{s}$ is the bulk density of the upper soil layer of the excavation face, and $\sigma_{v}$ is the overburden Earth pressure.

Combine formulas (2) and (3) and bring relevant parameters into

$$
\begin{aligned}
P_{s}= & \omega\left(B L \sigma_{v}+\frac{\sqrt{\pi} D_{1}^{2} D \gamma_{s} \cot \beta}{4}\right) \\
& -\left[\frac{c_{s} B D_{1}}{\sin \beta}+D_{1} L\left(c_{s}+k_{0} \overline{\sigma_{v}} \tan \varphi_{s}\right)\right](\omega \sin \beta+\cos \beta),
\end{aligned}
$$

where $\quad \omega=\left(\sin \beta-\tan \varphi_{s} \cos \beta / \cos \beta+\tan \varphi_{s} \sin \beta\right) \quad$ and other symbols are the same as above.

(2) Force Analysis of Wedge with Folded Surface. As shown in Figure 9, the sliding surface of the wedge in model 2 is not a plane, but a folding surface, so it is called "folding surface wedge" in this paper. In order to facilitate the stress analysis, the fracture wedge is divided into two parts: soil wedge and rock wedge. The interface is the interface of soil-rock composite stratum. The stress of the wedge is shown in Figure 12. In the figure, $V$ is the resultant force of the vertical overburden Earth pressure on the upper soil layer, $Q_{1}$ and $Q_{2}$ are the resultant force of the interaction between the soil layer and the rock layer, $P_{s}$ and $P_{r}$ are the total support pressure of the excavation face of the upper soil layer and the lower rock layer, respectively, $G_{s}$ and $G_{r}$ are the dead weight of soil wedge and rock wedge, respectively, $N_{1}$ and $N_{2}$ are the normal supporting force of soil and rock wedge on the slope, respectively, $T_{1}$ and $T_{3}$ are the friction forces on the slopes of the soil wedges and rock wedges, respectively, $T_{2}$ and $T_{4}$ are the friction on the sides of the soil wedges and rock wedges, respectively, $\beta_{1}$ and $\beta_{2}$ are the angles between the soil wedge and the rock layer wedge and the horizontal plane, and $D_{1}$ and $D_{2}$ are the thickness of the upper soil layer and the lower rock layer, respectively.

Let $\varepsilon_{2}=D_{1} / B$; then, $D_{1}=\varepsilon_{2} B$ and $D_{2}=\left(1-\varepsilon_{2}\right) B$, and $B$ is the equivalent shield diameter. In order to facilitate the derivation, assuming that the supporting force of the excavation surface is evenly distributed, $P_{s}=\varepsilon_{2} P$ and 


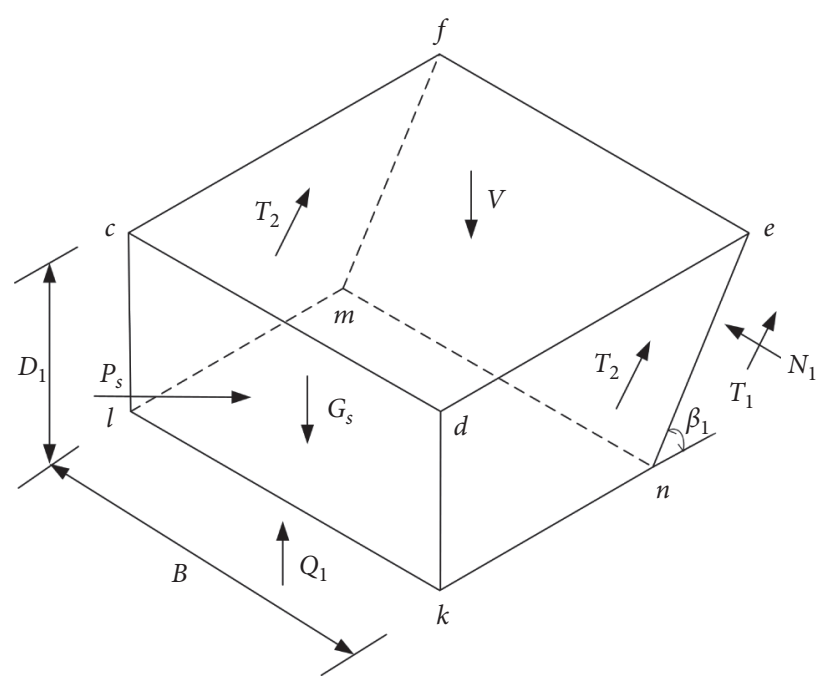

(a)

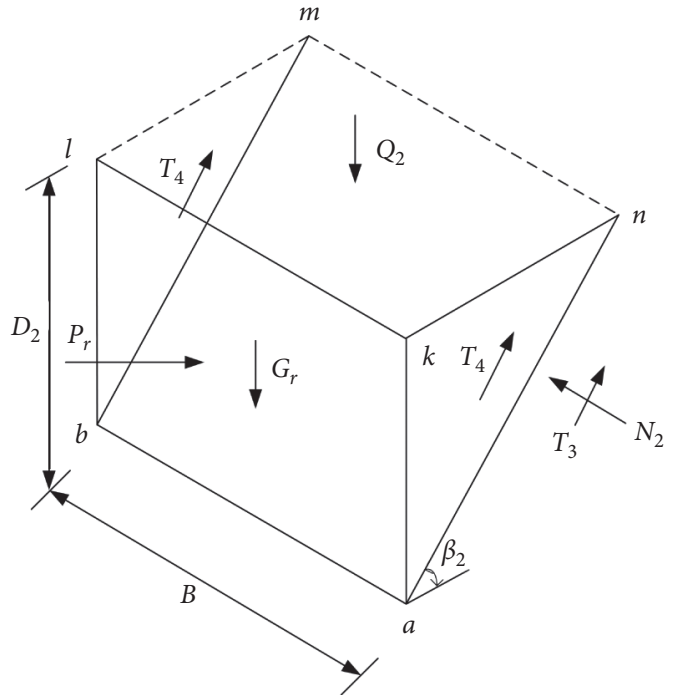

(b)

FIGURE 12: Stress diagram of wedge with broken surface. (a) Upper soil wedge. (b) Lower rock wedge.

$P_{r}=\left(1-\varepsilon_{2}\right) P$, where $P$ is the total supporting force of the excavation surface.

Considering the equilibrium of wedge, the force equilibrium equations of soil and rock wedge in horizontal and vertical directions are established, respectively. The solving process is as follows.

As shown in Figure 12(a), the upper soil wedge is analyzed for static equilibrium:

$$
P_{s}=\frac{V+G_{s}-Q_{1}-\left(\left(c_{s} B D_{1} / \sin \beta_{1}\right)+2 T_{2}\right)\left(\sin \beta_{1}+\mu \cos \beta_{1}\right)}{\mu},
$$

where $\mu=\left(\cos \beta_{1}+\tan \varphi_{s} \sin \beta_{1} / \sin \beta_{1}-\tan \varphi_{s} \cos \beta_{1}\right)$ and $c_{s}$ is the cohesion of the upper soil layer.

As shown in Figure 12(b), the lower rock strata wedgeshaped body is analyzed for static balance:

$$
\begin{aligned}
\sum F_{z}= & 0: G_{r} \\
& +Q_{2}-T_{3} \sin \beta_{2}-2 T_{4} \sin \beta_{2}-N_{2} \cos \beta_{2}=0 \\
\sum F_{x}= & 0: P_{r} \\
& +T_{3} \cos \beta_{2}+2 T_{4} \cos \beta_{2}-N_{2} \sin \beta_{2}=0 .
\end{aligned}
$$

$$
\begin{aligned}
\sum F_{z}= & 0: V \\
& +G_{s}-T_{1} \sin \beta_{1}-2 T_{2} \sin \beta_{1}-N_{1} \cos \beta_{1}-Q_{1}=0 \\
\sum F_{x}= & 0: P_{s} \\
& +T_{1} \cos \beta_{1}+2 T_{2} \cos \beta_{1}-N_{1} \sin \beta_{1}=0
\end{aligned}
$$

Combine vertical formulas (8) and (9) and eliminate $N_{1}$ to obtain
Combine vertical formulas (11) and (12) and eliminate $\mathrm{N}_{2}$ to obtain

$$
P_{r}=\frac{G_{r}+Q_{2}-\left(\left(c_{r} B D_{2} / \sin \beta_{2}\right)+2 T_{4}\right)\left(\sin \beta_{2}+\mu^{\prime} \cos \beta_{2}\right)}{\mu^{\prime}},
$$

where $\mu^{\prime}=\left(\cos \beta_{2}+\tan \varphi_{r} \sin \beta_{2} / \sin \beta_{2}-\tan \varphi_{r} \cos \beta_{2}\right)$ and $c_{r}$ is the cohesion of the lower strata.

According to the previous hypothesis, $P_{s}=\varepsilon_{2} P$, $P_{r}=\left(1-\varepsilon_{2}\right) P$, and $P=P_{s}+P_{r}$. And, because $Q_{1}=Q_{2}$, the total support force $P$ of active failure of tunnel excavation face in soil-rock composite stratum is finally obtained by 
sorting out the elimination term. The solution process is as follows.
Equations (10) and (13) are sorted out as follows:

$$
\left\{\begin{array}{l}
\mu \cdot \varepsilon_{2} P=V+G_{s}-Q_{1}-\left(\frac{c_{s} B^{2} \varepsilon_{2}}{\sin \beta_{1}}+2 T_{2}\right)\left(\sin \beta_{1}+\mu \cos \beta_{1}\right) \\
\mu^{\prime} \cdot\left(1-\varepsilon_{2}\right) P=G_{r}+Q_{2}-\left[\frac{c_{r} B^{2}\left(1-\varepsilon_{2}\right)}{\sin \beta_{2}}+2 T_{4}\right]\left(\sin \beta_{2}+\mu^{\prime} \cos \beta_{2}\right) .
\end{array}\right.
$$

Add the two formulas in formula (14) to obtain

$$
P=\frac{V+G_{s}+G_{r}-\left(\left(c_{s} B^{2} \varepsilon_{2} / \sin \beta_{1}\right)+2 T_{2}\right)\left(\sin \beta_{1}+\mu \cos \beta_{1}\right)-\left[\left(c_{r} B^{2}\left(1-\varepsilon_{2}\right) / \sin \beta_{2}\right)+2 T_{4}\right]\left(\sin \beta_{2}+\mu^{\prime} \cos \beta_{2}\right)}{\mu \cdot \varepsilon_{2}+\mu^{\prime} \cdot\left(1-\varepsilon_{2}\right)} .
$$

The solution of each parameter in equations (10) and (13) is introduced below:

(1) Wedge weight

Self-weight of soil wedge $G_{s}$ :

$$
G_{s}=\gamma_{s} B S_{\mathrm{kden}}=\frac{1}{2} \varepsilon_{2}^{2} \gamma_{s} B^{3} \cot \beta_{1}+\varepsilon_{2}\left(1-\varepsilon_{2}\right) \gamma_{s} B^{3} \cot \beta_{1} \text {. }
$$

Self-weight of rock wedge $G_{r}$ :

$$
G_{r}=\gamma_{r} B S_{\mathrm{akn}}=\frac{1}{2}\left(1-\varepsilon_{2}\right)^{2} \gamma_{r} B^{3} \cot \beta_{2},
$$

where $S_{\text {kden }}$ and $S_{\text {akn }}$ are the areas of $k d e n$ plane and akn plane, respectively.

(2) Shear force on wedge slope

Shear force $T_{1}$ on the slope of the soil wedge:

$$
\cdot T_{1}=S_{\text {nmfe }}\left(\sigma_{1} \tan \varphi_{s}+c_{s}\right)=N_{1} \tan \varphi_{s}+\frac{c_{s} B^{2} \varepsilon_{2}}{\sin \beta_{1}} \text {. }
$$

Shear force $T_{3}$ on the slope of the rock wedge:

$\cdot T_{3}=S_{\mathrm{abmn}}\left(\sigma_{2} \tan \varphi_{r}+c_{r}\right)=N_{2} \tan \varphi_{r}+\frac{c_{r} B^{2}\left(1-\varepsilon_{2}\right)}{\sin \beta_{2}}$,

where $S_{\text {nmfe }}$ and $S_{\text {abmn }}$ are the area of $n m f e$ plane and abmn plane, respectively, and $\sigma_{1}$ and $\sigma_{2}$ are the normal stress in nmfe plane and abmn plane, respectively.

(3) Shear force on the side of wedge:

According to assumption (4) that the vertical stress increases linearly with the depth, the calculation diagram of the shear force on the side of the wedge is shown in Figure 13.

It can be seen from Figure 13 that the vertical stresses at a certain depth on the sliding surface afn $(b l m)$ and fden $(l c f m)$ are as follows.

Sliding surface $f d e n(l c f m)$ :

$$
\left\{\begin{array}{l}
\sigma_{z s}=\sigma_{v}+\gamma_{s} z_{1} \\
0 \leq z_{1} \leq \varepsilon_{2} B
\end{array}\right.
$$

Sliding surface $a f n(b l m)$ :

$$
\left\{\begin{array}{l}
\sigma_{z r}=\sigma_{v}+\gamma_{s} \varepsilon_{2} B+\gamma_{r} z_{2}, \\
0 \leq z_{2} \leq\left(1-\varepsilon_{2}\right) B .
\end{array}\right.
$$

Then, the shear force $d T$ acting on the microelement plane is

$$
d T=\left[c+K \sigma_{z} \tan \varphi\right] d S .
$$

The total shear force $T$ acting on $a f n(b l m)$ and fden $(\mathrm{lcfm})$ can be obtained by integrating equation (22).

Sliding surface $f d e n(l c f m)$ : 


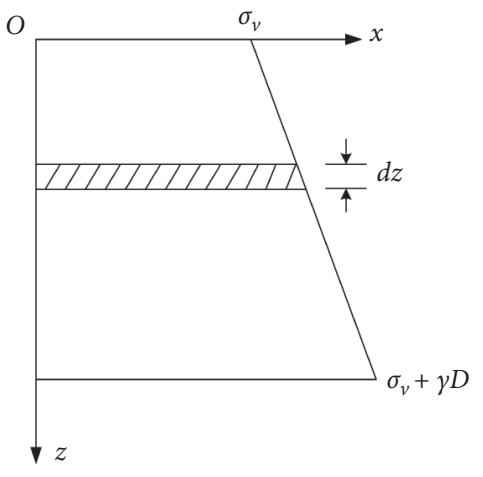

(a)

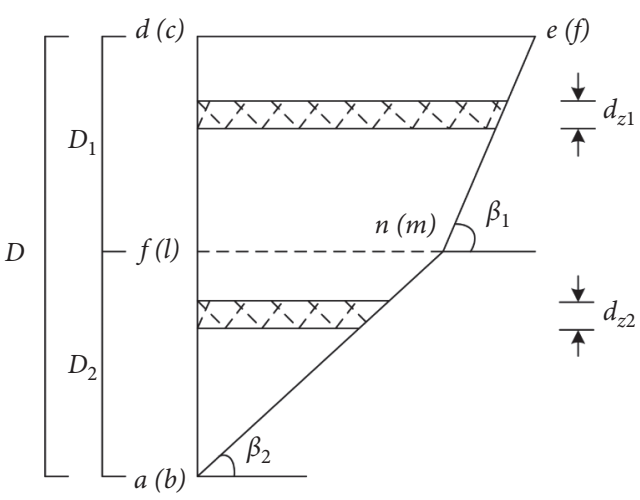

(b)

FIgURE 13: Calculation diagram of wedge side shear force. (a) Vertical stress distribution. (b) Area integral.

$$
\begin{aligned}
T_{2}= & T_{s}=\int_{0}^{\varepsilon_{2} B}\left[c_{s}+K \sigma_{z s} \tan \varphi_{s}\right] \cdot\left[\left(1-\varepsilon_{2}\right) B \cot \beta_{2}+\left(\varepsilon_{2} B-z_{1}\right) \cot \beta_{1}\right] \mathrm{d} z_{1} \\
= & \varepsilon_{2} B \cdot\left[\varepsilon_{2} B \cot \beta_{1}-B \cot \beta_{2}\left(\varepsilon_{2}-1\right)\right]\left(c_{s}+\tan \varphi_{s} \sigma_{v} K\right)-\varepsilon_{2}^{2} B^{2} \\
& \cdot\left\{\frac{\cot \beta_{1}\left(c_{s}+\tan \varphi_{s} \sigma_{v} K\right)}{2}-\frac{\tan \varphi_{s} K \gamma_{s}\left[\varepsilon_{2} B \cot \beta_{1}-B \cot \beta_{2}\left(\varepsilon_{2}-1\right)\right]}{2}\right\}-\frac{\varepsilon_{2}^{3} B^{3} \tan \varphi_{s} \cot \beta_{1} K \gamma_{s}}{3}
\end{aligned}
$$

Sliding surface $a f n(b l m)$ :

$$
\begin{aligned}
T_{4} & =T_{r}=\int_{0}^{\left(1-\varepsilon_{2}\right) B}\left[c_{r}+K \sigma_{z r} \tan \varphi_{r}\right] \cdot\left\{\left[\left(1-\varepsilon_{2}\right) B-z_{2}\right] \cot \beta_{2}\right\} \mathrm{d} z_{2} \\
& =\frac{\left[B^{2} \cot \beta_{2}\left(\varepsilon_{2}-1\right)^{2} \cdot\left(3 c_{r}+3 \tan \varphi_{r} \sigma_{v} K+B \tan \varphi_{r} K \gamma_{r}+3 \varepsilon_{2} B \tan \varphi_{r} K \gamma_{s}-\varepsilon_{2} B \tan \varphi_{r} K \gamma_{r}\right)\right]}{6} .
\end{aligned}
$$

(4) The resultant force of the overburden Earth pressure acting on the top of the wedge:

$$
V=\sigma_{v} S_{\text {cfed }}=\sigma_{v} B L
$$

where $S_{\text {cfed }}$ is the area of the cfed plane and $L$ is the length of the top of the sliding block, $L=D_{2} \cot \beta_{2}+D_{1} \cot \beta_{1}=$ $\left(1-\varepsilon_{2}\right) B \cot \beta_{2}+\varepsilon_{2} B \cot \beta_{1}$.

\subsection{Determination of Overburden Earth Pressure of Tunnel in} Soil-Rock Composite Stratum. In practical engineering, the soil conditions are changeable. The soil at the top of the tunnel does not necessarily move down vertically, and the sliding surface may be inclined. For example, the loose failure area at the upper part of the clay layer is "wide at the top and narrow at the bottom," which has been confirmed by many scholars and numerical simulation in this paper $[22,28]$. Although the literature [20] has carried out the derivation of the ultimate support force of the excavation face in the clay layer, it does not involve the improvement of the loose Earth pressure, and the selection of the calculation parameters is not accurate, which affects the universality and rationality of the calculation results. Therefore, it is necessary to expand the application of the formula.

3.3.1. Two-Dimensional Expansion of Terzaghi Loose Earth Pressure. Terzaghi thinks that it is not easy to calculate $A B$ and $C D$ curves. Even if they are calculated, the later calculation will become very complicated. Therefore, it is almost assumed that $A B$ and $C D$ are two vertical straight lines. In order to calculate the overburden Earth pressure realistically and accurately, the failure track lines $A B$ and $C D$ are assumed to be two straight lines not perpendicular to the ground surface, and the angle between $A B, C D$, and the ground surface depends on the actual project. The calculation model of the corresponding loose Earth pressure is shown in Figure 14.

In Figure 14, it is assumed that the width of the soil strip varies with the depth, and there is a linear relationship between them. It can be seen that when $A B$ and $C D$ are not perpendicular to the surface, the derived problem is how to 


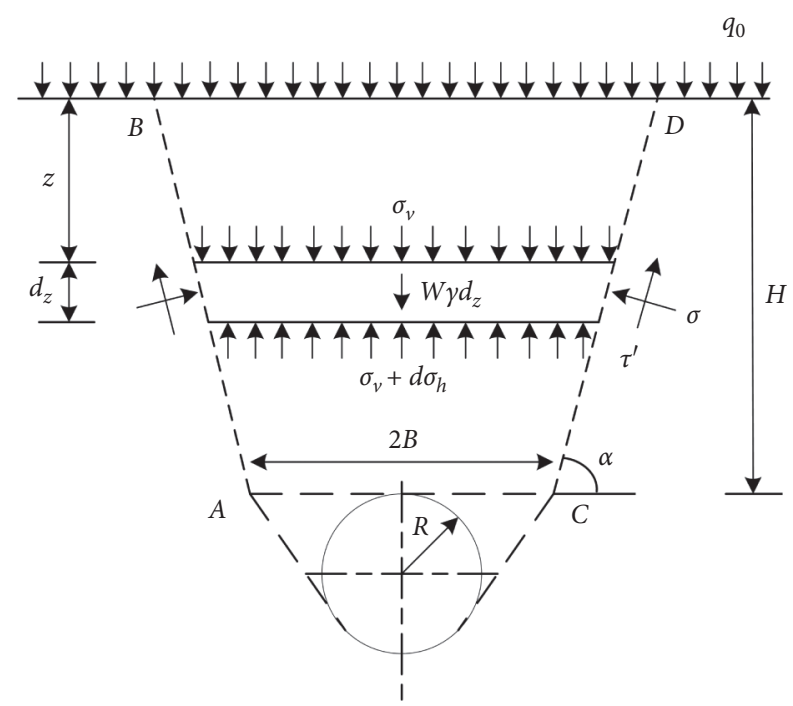

FIgURE 14: Calculation diagram of expanded loose Earth pressure.

solve the normal stress $\sigma$ and the lateral friction $\tau^{\prime}$ acting on the side of the element. Therefore, the ratio of normal stress $\sigma$ to vertical stress $\sigma_{v}$ on the side of the element is assumed to be the slope stress coefficient $K \prime$; then, $\sigma=K I \cdot \sigma_{v}$ and $\tau^{\prime}=c+K I \cdot \sigma_{v} \cdot \tan \varphi$, where $c$ and $\varphi$ are cohesion and internal friction angle of soil, respectively.

The calculation idea is the same as Terzaghi's loose Earth pressure theory, and the vertical force balance equation is established as

$$
\begin{aligned}
W \sigma_{v}+W \gamma d z= & W\left(\sigma_{v}+d \sigma_{v}\right)+2 c \sin \alpha d z \\
& +2 K^{\prime} \sigma_{v} \tan \varphi \sin \alpha d z+2 K^{\prime} \sigma_{v} \cos \alpha d z
\end{aligned}
$$

where $W$ is the width of soil strip, $W=2 B+2(H-z) \cot \alpha$, and $H$ is the length of soil strip, and $W \geq 2 B$.

Organize the available equation:

$$
\begin{array}{r}
{[B+(H-z) \cot \alpha] \frac{d \sigma_{v}}{d z}+K^{\prime}(\tan \varphi \sin \alpha+\cos \alpha),} \\
\sigma_{v}=(H-z) \gamma \cot \alpha+B \gamma-c \sin \alpha .
\end{array}
$$

Solve the differential equation, and according to the known boundary conditions $z=0$ and $\sigma_{v}=q_{0}$, the loose Earth pressure $\sigma_{v}$ at any depth is obtained as

$$
\begin{aligned}
\sigma_{v}= & \frac{(n-K / c \sin 2 \alpha) / 2-K^{\prime} c \tan \varphi / 2+l+B K^{\prime} \gamma \cos \alpha+k+B \gamma m+H \gamma \cot \alpha m}{\left(K^{\prime} \cos \alpha+m\right)\left(K^{\prime} \cos \alpha-\cot \alpha+m\right)} \\
+ & \frac{q_{0}-\left(n-K^{\prime} c \sin 2 \alpha / 2-K^{\prime} c \tan \varphi / 2+l+B K^{\prime} \gamma \cos \alpha+k+B \gamma m+H K^{\prime} \gamma \cot \alpha \sin \alpha \tan \varphi\right)}{\left(K^{\prime} \cos \alpha+m\right)\left(K^{\prime} \cos \alpha-\cot \alpha+m\right)} \\
& \cdot \frac{(z \cdot \cos \alpha-B \sin \alpha-H \cos \alpha)^{p}}{(-H \cos \alpha-B \sin \alpha)^{p}}-\frac{\gamma \cot \alpha \cdot z}{K^{\prime} \cos \alpha-\cot \alpha+m} .
\end{aligned}
$$

Because formula (28) is too lengthy, in order to simplify the formula, $k, l, m$, and $n$ are used to replace some of the formulas in the formula, where $k=H K^{\prime} \gamma \cos \alpha \cot \alpha$, $l=K I c \cos 2 \alpha \tan \varphi / 2, \quad m=K^{\prime} \sin \alpha \tan \varphi, n=c \cot \alpha \sin \alpha$, and $p=K^{\prime}[\sin (2 \alpha-\varphi)+\sin \varphi] / 2 \cos \alpha \cos \varphi$, where $K^{\prime}$ is the stress coefficient of the inclined plane and $\alpha$ is the angle between $A B$ and $C D$ and the horizontal plane.

\subsubsection{Three-Dimensional Application of Terzaghi's Loose} Earth Pressure. The loose Earth pressure model in the threedimensional space is shown in Figure 10.

According to the three-dimensional loose Earth pressure calculation model in Figure 10, the vertical stress balance equation is established by using two-dimensional microelement (Figure 14):

$$
\begin{aligned}
S \sigma_{v}+S \gamma d z= & S\left(\sigma_{v}+d \sigma_{v}\right)+C K^{\prime} \sigma_{v} \tan \varphi \sin \alpha d z \\
& +C c \sin \alpha d z+C K^{\prime} \sigma_{v} \cos \alpha d z,
\end{aligned}
$$

where $S$ is the area of the microelement, $S=[B+2(H-z) \cot \alpha] \cdot[L+2(H-z) \cot \alpha], C$ is the perimeter of the microelement, $C=2[B+L+4(H-z) \cot \alpha]$, $\alpha$ is the angle between the four planes of the inverted pyramid and the horizontal plane, $0<\alpha<90^{\circ}$, and $K^{\prime}$ is the stress coefficient of the inclined plane, which is obtained by the element stress analysis method [28]:

$$
K^{\prime}=\frac{\sigma}{\sigma_{v}}=K \sin ^{2} \alpha+\cos ^{2} \alpha
$$

where $K$ is the lateral pressure coefficient of overlying soil, which is in accordance with $K=1-\sin \varphi$ [29].

The finishing formula (29) is available:

$$
\begin{aligned}
{[B} & +2(H-z) \cot \alpha] \cdot[L+2(H-z) \cot \alpha] \frac{\mathrm{d} \sigma_{v}}{\mathrm{~d} z}+2[B+L+4(H-z) \cot \alpha] K^{\prime} \cdot(\tan \varphi \sin \alpha+\cos \alpha) \sigma_{v} \\
& =[B+2(H-z) \cot \alpha] \cdot[L+2(H-z) \cot \alpha] \gamma-2[B+L+4(H-z) \cot \alpha] c \sin \alpha .
\end{aligned}
$$


Solve the first-order inhomogeneous differential equation, and according to the known boundary conditions $z=0$ and $\sigma_{v}=q_{0}$, the loose Earth pressure $\sigma_{v}$ at any depth is obtained as

$$
\begin{aligned}
\sigma_{v}= & \gamma \cdot\{[B+2(H-z) \cot \alpha] \cdot[L+2(H-z) \cot \alpha]\}^{K^{\prime} \tan \alpha \cdot(\tan \varphi \sin \alpha+\cos \alpha)} \\
& \cdot \int_{0}^{z}\{[B+2(H-z) \cot \alpha] \cdot[L+2(H-z) \cot \alpha]\}^{-K^{\prime} \tan \alpha \cdot(\tan \varphi \sin \alpha+\cos \alpha)} \mathrm{d} z \\
& +\left[\frac{c \sin \alpha}{K^{\prime} \cdot(\tan \varphi \sin \alpha+\cos \alpha)}+q_{0}\right] \cdot\left\{\frac{[B+2(H-z) \cot \alpha] \cdot[L+2(H-z) \cot \alpha]}{[B+2 H \cot \alpha] \cdot[L+2 H \cot \alpha]}\right\}^{K^{\prime} \tan \alpha \cdot(\tan \varphi \sin \alpha+\cos \alpha)} \\
& -\frac{c \sin \alpha}{K^{\prime} \cdot(\tan \varphi \sin \alpha+\cos \alpha)}
\end{aligned}
$$

Therefore, in the calculation model of ultimate support force in soil-rock composite stratum, the calculation formula of loose Earth pressure proposed in this paper should be adopted, and the total support pressure of the upper soil layer in excavation face of soil-rock composite stratum can be obtained by introducing formula (32) into (9) and (25).

\subsection{Analysis of Ultimate Supporting Force}

3.4.1. Theoretical Model Solving. In the model of twofold plane wedge model, the inclination angles of two sliding blocks are involved, so solving the limit support force in the theoretical model becomes the problem of solving the extreme value of two variables [28]. Because the formula is complex and difficult to calculate, the author uses MATLAB and Mathematica to solve it. By setting two cycles of $\beta_{1}$ and $\beta_{2}$ bivariates for traversal optimization, the accuracy requirements in the process of optimization can be set according to the requirements. In order to ensure the construction safety, the maximum value should be taken as the ultimate support force of the excavation face.

3.4.2. Verification of Calculation Model. In order to verify the accuracy and rationality of the above two wedge calculation models, the numerical simulation results of this paper are used to test the results of the wedge calculation model. The comparison results are shown in Table 2. The "wedge angle" $\beta$ corresponding to the ultimate support force refers to the calculation model, which uses Terzaghi's loose Earth pressure theory (or expansion) to calculate the ultimate support force.

It can be seen from Table 2 that the ultimate support force calculated by the Terzaghi loose Earth pressure theory developed in this paper is closer to the numerical simulation result, while the result calculated by the full overburden soil weight is much larger than the numerical simulation result. Therefore, in this kind of composite stratum, when the thickness of overburden is about one time of the tunnel diameter, the Terzaghi loose Earth pressure theory developed in this paper should be used to calculate the ultimate support force.

\section{Engineering Case Analysis}

4.1. Project Overview. The section from Mengjiazhuang station to Long Ao station of Jinan Metro Line 3 is located in Lixia District of Jinan City. The section tunnel is a standard singlehole single-line circular section, which is constructed by the shield method. The left and right lines of the section plane line are composed of straight line section, three circular curve sections, and transition curve sections with radius of $R=1000 \mathrm{~m}$, respectively. The line spacing is $13 \sim 14 \mathrm{~m}$, and the covering soil thickness is $2.3 \sim 80 \mathrm{~m}$. It is worth mentioning that the groundwater environment in Jinan City is complex and changeable due to the large number of springs. Liu et al. $[30,31]$ carried out a series of studies to accurately predict the groundwater inflow in the tunnel, which can provide theoretical support for similar water rich projects.

\subsection{Instability Calculation and Analysis}

4.2.1. Establishment of Calculation Model. The vault buried depth of this bid section is about $7.0 \mathrm{~m}$. In this calculation, the geotechnical materials follow Mohr-Coulomb criterion, the combination of soil-rock composite strata is shown in Figure 15, and the values of geotechnical parameters are shown in Table 3.

The length of the model is $50 \mathrm{~m}$ in $X$ direction, $30 \mathrm{~m}$ in $Y$ direction, and $34 \mathrm{~m}$ in $Z$ direction [21]. ABAQUS finite element meshing is shown in Figure 16. The diameter of shield excavation $D$ is $6.4 \mathrm{~m}$, and the buried depth of tunnel vault $C$ is $7 \mathrm{~m}$. The numerical simulation method is described in the test scheme in Section 2. According to the tunneling parameters of the actual shield project and the static Earth pressure strength formula [23], the trapezoidal support stress applied on the excavation face is calculated, $p=98800-9000 \cdot z$, in $\mathrm{Pa}$, where $z$ is the thickness of the rock and soil layer in front of the excavation face, $z \leq 6 \cdot 4$, in $m$. 
TABLE 2: Comparison between numerical simulation results of soil-rock composite stratum and wedge calculation model.

\begin{tabular}{|c|c|c|c|c|}
\hline \multirow{2}{*}{$\begin{array}{l}\text { Stratigraphic } \\
\text { combination }\end{array}$} & \multirow{2}{*}{$\begin{array}{l}\text { Calculation theory of overburden } \\
\text { Earth pressure }\end{array}$} & \multirow{2}{*}{$\begin{array}{l}\text { Vertical overburden Earth } \\
\text { pressure }(\mathrm{kPa})\end{array}$} & \multicolumn{2}{|c|}{ Limit support pressure $(\mathrm{kPa})$} \\
\hline & & & $\begin{array}{l}\text { Calculation model } \\
\text { results }\end{array}$ & $\begin{array}{c}\text { Numerical simulation } \\
\text { results }\end{array}$ \\
\hline Clay & Theory of fully covered soil & 126.08 & 53.83 & \\
\hline $\begin{array}{l}\text { Moderately weathered } \\
\text { limestone }\end{array}$ & $\begin{array}{c}\text { Terzaghi's theory of loose Earth } \\
\text { pressure }\end{array}$ & 29.29 & 8.26 & 4.68 \\
\hline Clay & Theory of fully covered soil & 126.08 & 50.42 & \\
\hline $\begin{array}{l}\text { Strongly weathered } \\
\text { mudstone }\end{array}$ & $\begin{array}{c}\text { Terzaghi's theory of loose Earth } \\
\text { pressure }\end{array}$ & 35.17 & 3.71 & 4.90 \\
\hline
\end{tabular}

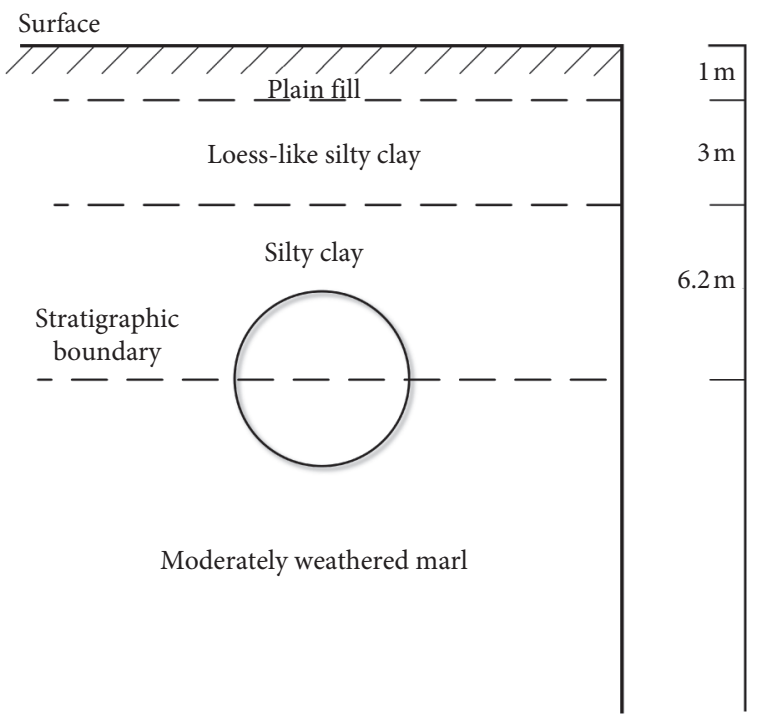

FIGURE 15: Schematic diagram of tunnel section position.

TABLE 3: Table of geotechnical parameters.

\begin{tabular}{lccccc}
\hline Name & Density $(\mathrm{kg} / \mathrm{m} 3)$ & Elastic modulus $(\mathrm{MPa})$ & Poisson's ratio & Cohesion $(\mathrm{kPa})$ & Internal friction angle $\left(^{\circ}\right)$ \\
\hline Plain fill & 1940 & 3 & 0.25 & 12.6 & 14.2 \\
Loess-like silty clay & 1910 & 8 & 0.21 & 16.4 & 11.9 \\
Silty clay & 1960 & 5 & 0.30 & 19.4 & 12.9 \\
Moderately weathered marl & 2500 & 2590 & 0.24 & 150 & 32 \\
\hline
\end{tabular}

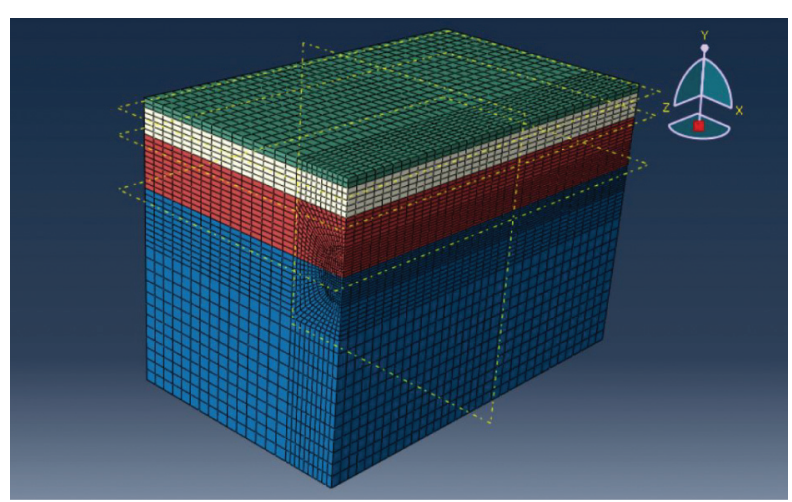

Figure 16: Gridding graph. 


\subsubsection{Analysis of Calculation Results}

(1) Active Failure Mode. The soil displacement in front of the shield excavation face corresponding to the last analysis step is shown in Figure 17.

It can be seen from the figure that the silty clay layer in front of the shield tunnel face deforms and gradually expands to the surface, and the scope gradually increases; however, the moderately weathered marl layer does not show obvious deformation due to its high strength. Similar to Section 2, the deformation of the rock and soil in front of the excavation surface starts from the upper soft soil layer, while the lower moderately weathered marl layer has no obvious deformation, and the final instability form shows an inverted trapezoid with wide upper and narrow lower.

(2) Change of Stress Field. With the decrease of the support stress of the excavation face, the stress field of the surrounding rock and soil also changes. When the support pressure of the excavation face of the shield tunnel is reduced to 0 bar, the stress field of the rock and soil is shown in Figure 18.

It can be seen from the stress cloud diagram that, as the soil near the excavation surface moves into the pressure chamber, the soil stress decreases due to the unloading effect of excavation, showing a certain stress release phenomenon. In addition, the stress of the soil is transferred to the nearby soil with a small displacement, showing a weak arching effect. The side confirms that the arching ability of the clay layer is weaker than that of the sand layer.

4.2.3. Analytical Model Analysis. According to the previous numerical simulation results, the author draws an approximate three-dimensional model of the instability of the shield excavation face under this working condition, as shown in Figure 19.

It can be seen that, under this working condition, the ultimate support force of the shield excavation face should be calculated by model 1 in Section 2 of this paper, and the overlying Earth pressure should be calculated by the extended Terzaghi loose Earth pressure formula. Incorporating the calculated parameters into formulas (9) and (32), the value of the ultimate supporting force $\sigma_{s}$ at the middle position of the wedge is obtained

\subsection{Analysis of Influencing Factors of Ultimate Support Force} in Soil-Rock Composite Stratum. In order to further understand the wedge model of soil-rock composite stratum, the sensitivity analysis of several main parameters affecting the ultimate support force of shield excavation face is carried out. The calculation parameters are as follows: buried depth $H=7.0$ $\mathrm{m}$, diameter $D=6.4 \mathrm{~m}, \gamma_{\text {wedge }}=\gamma_{\text {prism }}=19.36 \mathrm{kPa}, \varphi$ wedge $=$ $\varphi_{\text {prism }}=12.6^{\circ}$, and $c_{\text {wedge }}=c_{\text {prism }}=14.5 \mathrm{kPa}$.

4.3.1. The Influence of "Wedge Angle". In the calculation of the wedge model in this paper, the author obtains the excavation face support force values under different

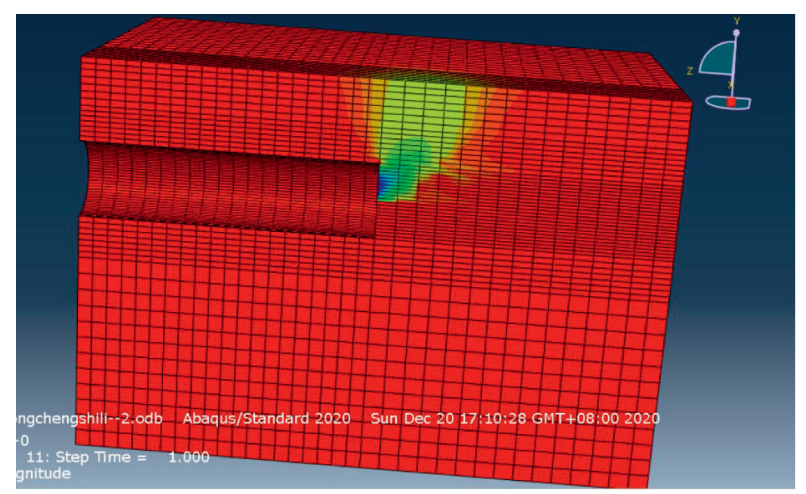

FIGURE 17: Displacement nephogram.

wedge angles by changing the "wedge angle" and finally takes the maximum value of the above support force as the excavation face limit support force through repeated iteration with MATLAB. The results are shown in Figure 20.

It can be seen from Figure 20 that the value of the support force is closely related to the "wedge angle" $\beta$. With the increase of the "wedge angle" $\beta$, the support force gradually reaches the maximum and then gradually decreases after reaching the peak.

4.3.2. Influence of Overburden Earth Pressure. In order to study the influence of overburden Earth pressure on the calculation results of ultimate support force, sensitivity analysis of the influence of overburden Earth pressure on ultimate support force is carried out in this section. The relationship between them is shown in Figure 21.

It can be seen that the ultimate support force decreases linearly with the increase of overburden Earth pressure. When the overburden Earth pressure is calculated by the full overburden Earth weight, the ultimate support pressure is $75.56 \mathrm{kpa}$; when the overburden Earth pressure is calculated by Terzaghi loose Earth pressure formula, the ultimate support force is reduced to $2.00 \mathrm{kpa}$.

4.3.3. Influence of Tunnel Buried Depth. Figure 22 shows the relationship between the ultimate support force and the depth of shield. It can be seen that, with the increase of buried depth, the ultimate support force increases nonlinearly. Therefore, the influence of buried depth on the ultimate support force gradually decreases with the increase of buried depth.

4.3.4. the Influence of Cohesion. Figure 23 shows the relationship between ultimate supporting force and cohesion. The relationship between the two is the increase of cohesion and the linear decrease of the ultimate supporting force. When the cohesive force increases to $16 \mathrm{kpa}$, the ultimate supporting force decreases to $0 \mathrm{pa}$, indicating that the excavation surface can achieve selfstability without supporting force. It can be seen that when the cohesive force of the excavated stratum is large 


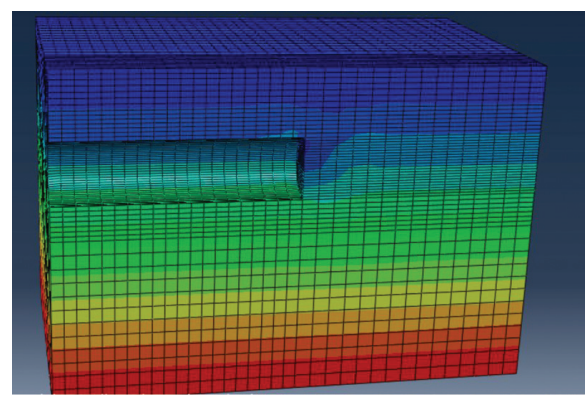

(a)

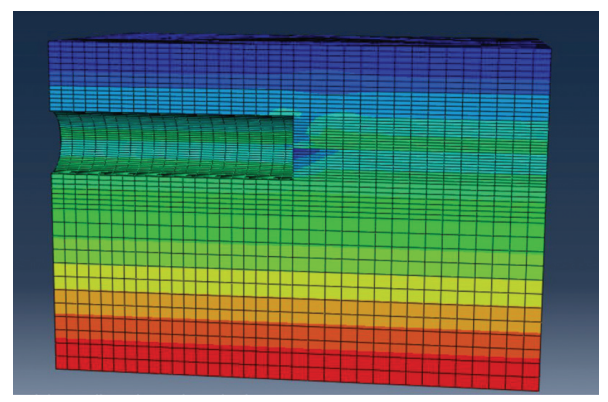

(b)

FIgURE 18: Stress nephogram at $\lambda=0$. (a) Vertical stress. (b) Horizontal stress.

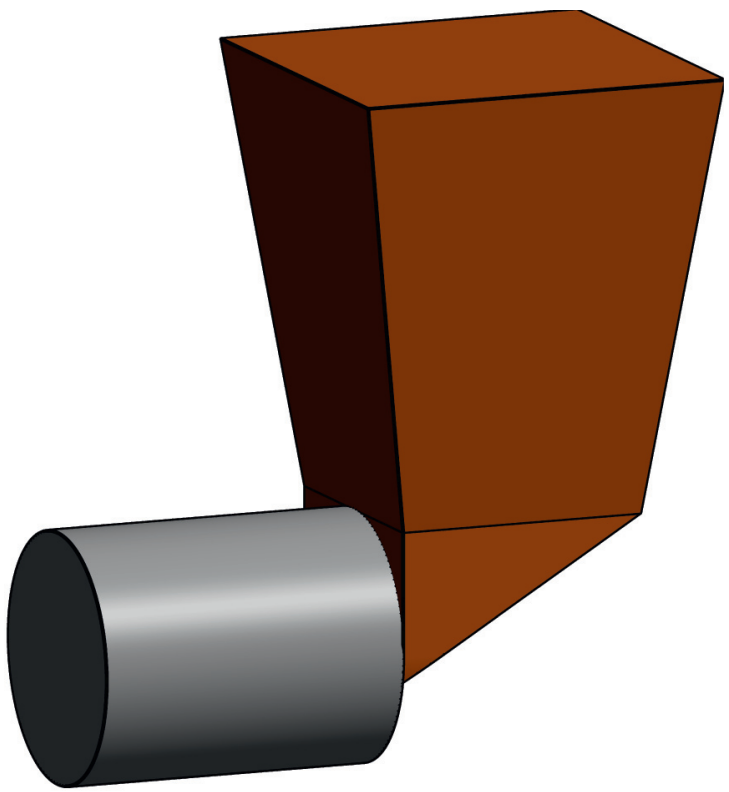

FIGURE 19: 3D model of excavation face instability.

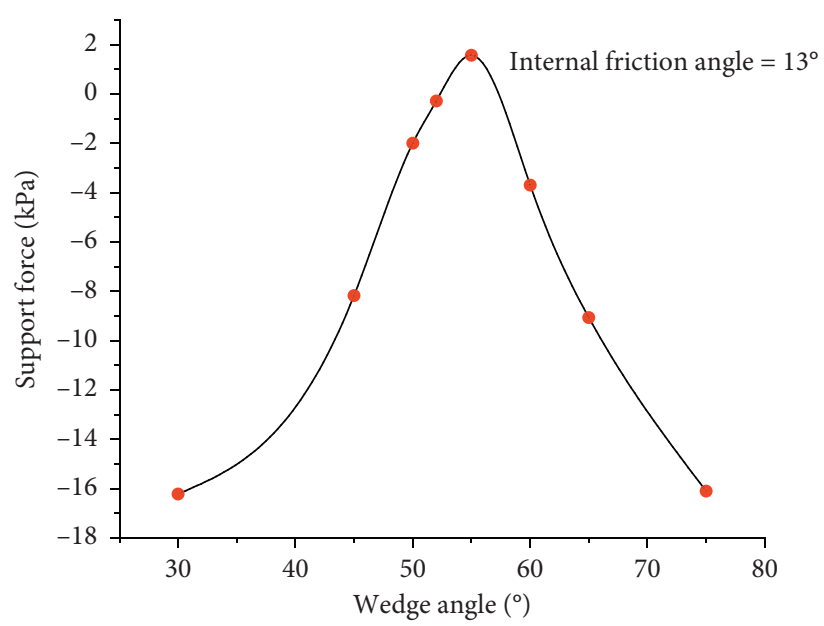

Figure 20: Relationship between support force and wedge angle. 


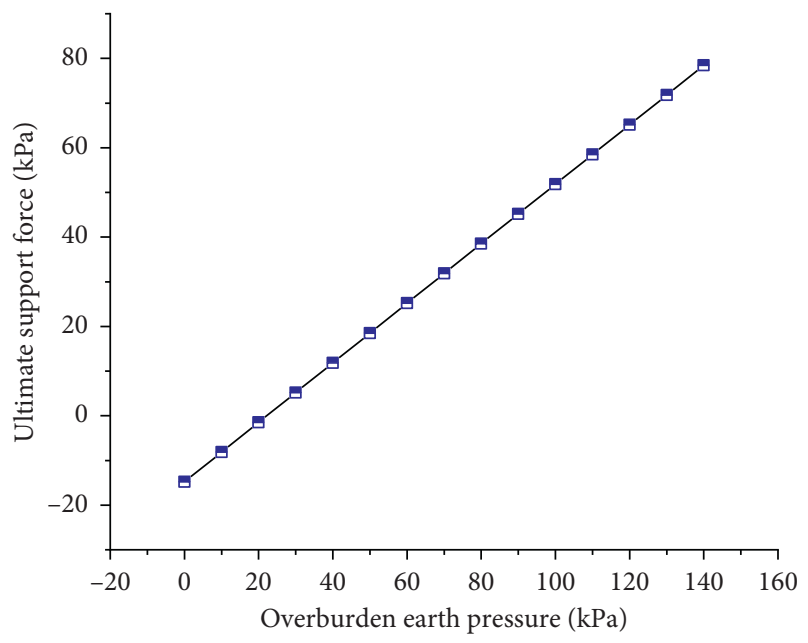

FIgURE 21: Relationship between ultimate support force of excavation face and overlying Earth pressure.

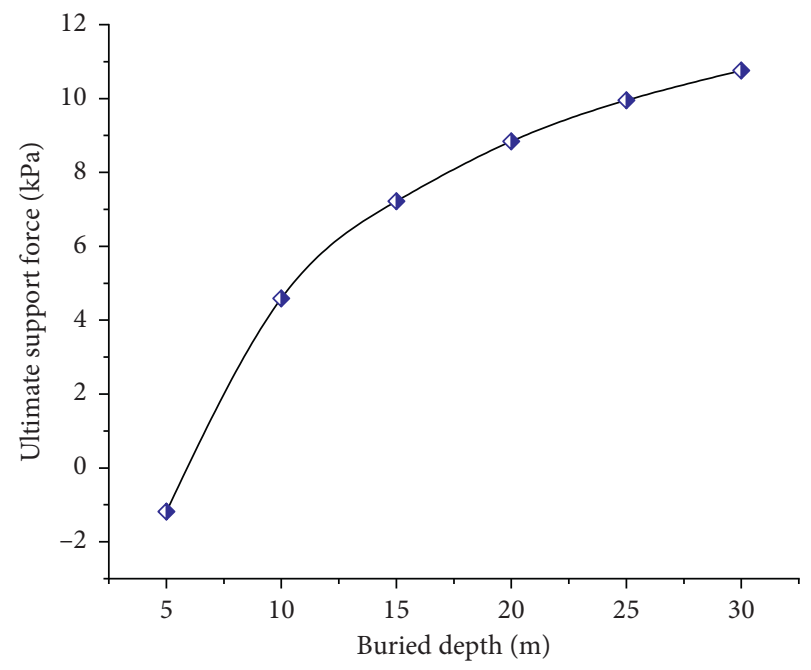

FIgURE 22: Relationship between ultimate support force of excavation face and buried depth.

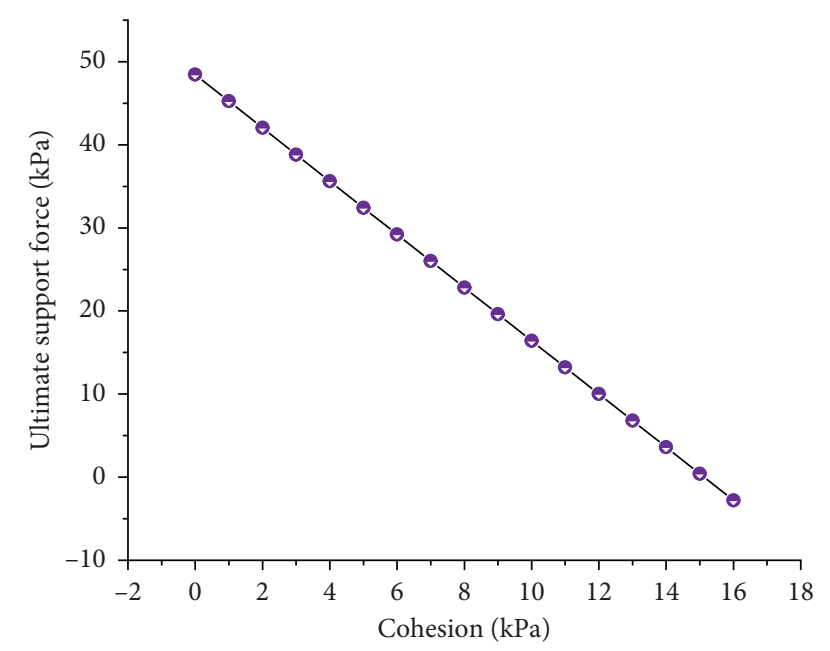

FIGURE 23: Relationship between ultimate support force and cohesion of the excavation face.

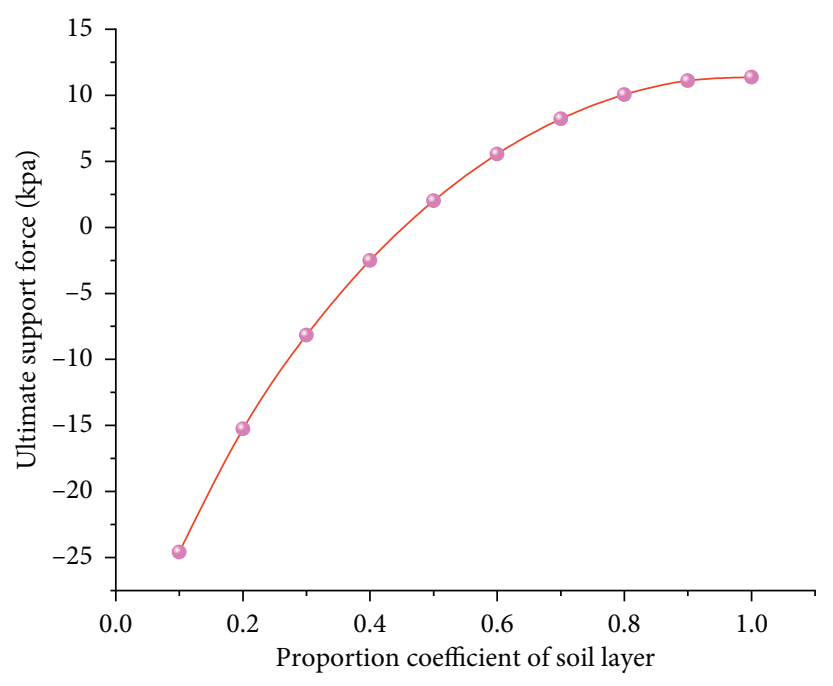

FIGURE 24: Relationship between ultimate support force of the excavation face and proportion coefficient of the soil layer.

and the groundwater is low, the surrounding rock of the tunnel has a certain self-stability ability, and it is recommended to choose the open mode of excavation.

4.3.5. The Influence of Soil Thickness Ratio Coefficient $\varepsilon$. In order to study the relationship between the thickness of the upper soil layer and the ultimate support force in the middle of the local wedge in the soil-rock composite stratum, the proportional coefficient of the soil layer thickness is introduced, $\varepsilon=D_{1} / B$, where $D_{1}$ is the thickness of the silty clay layer in front of the excavation face, and $\varepsilon<1$.

Figure 24 shows the relationship between the ultimate supporting force and the proportional coefficient of the soil layer. It can be seen that, with the increase of soil proportion coefficient, the ultimate support force increases nonlinearly, and the increasing rate decreases gradually.

\section{Conclusions}

Based on the summary and analysis of domestic and foreign research results, this paper uses numerical simulation and theoretical analysis to systematically study the stability of shield tunnel excavation surface in soil-rock composite strata and obtain some preliminary conclusions:

(1) In the soil-rock composite stratum, the simulation results show that the shape of "unloading loose area" is mainly determined by the properties of the upper soil layer, and the properties of the lower rock layer mainly determine the scope and shape of the "sliding instability area," which has little effect on the upper "unloading loose area." When the solid coefficient of the lower strata is large, the sliding instability area starts from the interface between the soil and the strata, showing a "local wedge;" when the solid coefficient of the lower strata is small, the sliding instability area starts from the bottom of the shield, showing a "folded wedge." 
(2) In fact, the shape of the slip surface is closely related to the properties of rock and soil. Through simple mathematical derivation, Terzaghi's formula of loose Earth pressure is extended to the case of inclined sliding surface; based on the previous calculation concept of the wedge model, combined with the numerical calculation results of instability failure mode of shield excavation face in Section 2 of this paper, the analytical formula of instability limit support force of shield excavation face in soil-rock composite stratum is deduced. The numerical simulation preliminarily verifies that the calculation method proposed in this paper is reliable.

(3) The case study shows that the displacement of the upper soil layer should be paid more attention when the shield tunneling in the "upper sticky and lower hard" composite stratum. In addition, when the stability of the upper soil layer is good, that is, the internal friction angle and cohesion of the soil are large, and the underground water pressure is not high, the open or semiopen tunneling mode is recommended to give full play to the tunneling ability of the shield.

\section{Data Availability}

The data used to support the findings of this study are available from the corresponding author upon request.

\section{Conflicts of Interest}

The authors declare no conflicts of interest.

\section{Acknowledgments}

This work was supported by the Ministry of Education of Humanities and Social Science Foundation of China (no. 20YJAZH022).

\section{References}

[1] X. F. He, Research on the disturbance mechanism and courter measures of shield tunnel crossing upper-soft lower-hard stratum, Ph.D. Thesis, Southwest Jiaotong University, Chengdu, China, 2017.

[2] Y. Song and A. Li, "Research and application of mud proportioning optimization of slurry balance shield in mudstone and gravel composite stratum," Rock and Soil Mechanics, vol. 41, no. 12, pp. 4054-4062+4072, 2020, in Chinese.

[3] Y. H. Lv, "The overall design and key techniques of the Yangtze river-crossing tunnel of Wuhan metro line 8," Railway Standard Design, vol. 65, no. 2, pp. 1-7, 2021, in Chinese.

[4] W. P. Luo, D. J. Yuan, and D. L. Jin, "Prediction and analysis of slurry pressure at the shield cut in composite strata based on random forest," China Civil Engineering Journal, vol. 53, no. S1, pp. 43-49, 2020, in Chinese.

[5] S. G. Song, Study on face stability and control technology of ebp shield-driving tunnel in composite ground with consideration of seepage condition, Ph.D. Thesis, Shandong University, Jinan, China, 2016.
[6] J. Zhang, Y. Liang, and T. G. Feng, "Investigation of the cause of shield-driven tunnel instability in soil with a soft upper layer and hard lower layer," Engineering Failure Analysis, vol. 118, Article ID 104832, 2020.

[7] Q. Huang, J. F. Zou, and Z. H. Qian, "Seismic stability analysis of tunnel face in purely cohesive soil by a pseudo-dynamic approach," Geomechanics and Engineering, vol. 23, no. 1, pp. 1-13, 2020, in Chinese.

[8] Y. Y. Yang, Q. H. Zhou, H. A. Li, and X. G. Huang, "Analysis of face stability during excavation of double-o-tube shield tunnel," Scientific World Journal, vol. 2013, Article ID 781968, 14 pages, 2013.

[9] Y. Su, G.-F. Wang, and Q.-H. Zhou, "Tunnel face stability and ground settlement in pressurized shield tunnelling," Journal of Central South University, vol. 21, no. 4, pp. 1600-1606, 2014, in Chinese.

[10] Z. Zheng, R. T. Liu, and S. C. Li, "Tunnel face failure mechanism with sand layer partial collapse," Arabian Journal of Geosciences, vol. 13, no. 20, pp. 1-11, 2020.

[11] M. Horn, "Horizontal earth pressure on perpendicular tunnel face," in Proceedings of the Hungarian National Conference of the Foundation Engineer Industry, pp. 7-16, Budapest, Hungary, May 1961.

[12] S. Janeseez and W. Steiner, "Face support for a large mixshield in heterogeneous ground conditions," Tunnelling, vol. 9, 1994.

[13] G. Angnostou and K. Kvoarl, "Face stability conditions with earth-pressure-balanced shields," Tunnelling and Underground Space Technology, vol. 11, no. 2, pp. 165-173, 1996.

[14] D. Liu, Study on stability of tunnel excavation face for ebp shield machine in composite ground, Ph.D. Thesis, Huazhong University of Science and Technology, Wuhan, China, 2009.

[15] W. Broere, Tunnel face stability and new cpt applications, Ph.D. Thesis, Delft University Press, Amsterdam, Netherlands, 2001.

[16] W. Broere, "Face stability calculation for a slurry shield in heterogeneous soft soils," in Proceedings of the World Tunnel Congress 98 on Tunnels and Metropolises, pp. 215-218, Sao Paulo, Brazil, April 1998.

[17] J. Shahmoradi, H. S. Rad, and P. Roghanchi, "Face stability analysis for the earth pressure balance method in nonhomogeneous inclined soil layers: case study," International Journal of Geomechanics, vol. 20, no. 10, Article ID 05020005, 2020.

[18] Y. Z. Hernandez, A. D. Farfan, and A. P. Assis, "Three-dimensional analysis of excavation face stability of shallow tunnels," Tunnelling and Underground Space Technology, vol. 92, Article ID 103062, 2019.

[19] Z. X. Zhang and W. Hu, "Investigation on excavation face support pressure calculation methods of shield tunnelling in clayey soil," Chinese Journal of Rock Mechanics and Engineering, vol. 33, no. 3, pp. 606-614, 2014, in Chinese.

[20] A. Li and D. L. Zhang, "Theoretical solution of ultimate support force of shield tunnel excavation face in cohesive soil layer," Railway Engineering, vol. 59, no. 4, pp. 71-75, 2019, in Chinese.

[21] R. P. Chen, L. Z. Qi, and L. J. Tang, "Study of limit supporting force of excavation face's passive failure of shield tunnels in sand strata," Chinese Journal of Rock Mechanics and Engineering, vol. 32, no. S1, pp. 2877-2882, 2013, in Chinese.

[22] J. S. Qin, Study on face deformation and collapse of earth pressure shield tunnel, Ph.D. Thesis, HoHai University, Nanjing, China, 2005. 
[23] D. L. Qian, Soil Mechanics, China Construction Industry Press, Beijing, China, 2009, in Chinese.

[24] A. S. N. Alagha and D. N. Chapman, "Numerical modelling of tunnel face stability in homogeneous and layered soft ground," Tunnelling and Underground Space Technology, vol. 94, Article ID 103096, 2019.

[25] R.-P. Chen, J. Li, L.-G. Kong, and L.-J. Tang, "Experimental study on face instability of shield tunnel in sand," Tunnelling and Underground Space Technology, vol. 33, pp. 12-21, 2013.

[26] Q. Chen, Study on support pressure at excavation face of shield tunneling in composite ground with soft and underlying hard strata, Ph.D. Thesis, Huazhong University of Science and Technology, Wuhan, China, 2010.

[27] I.-M. Lee, J.-S. Lee, and S.-W. Nam, "Effect of seepage force on tunnel face stability reinforced with multi-step pipe grouting," Tunnelling and Underground Space Technology, vol. 19, no. 6, pp. 551-565, 2004.

[28] J. Y. Li, Model test and theoretical studies on face instability of shallow shield tunnel, Ph.D. Thesis, ZheJiang University, Hangzhou, China, 2017.

[29] Y. Song, "Study on the stability model test and ultimate support pressure of shield tunnel in sand gravel composite stratum," Chinese Journal of Geotechnical Engineering, vol. 42, no. 12, pp. 2206-2214, 2020, in Chinese.

[30] X.-X. Liu, S.-L. Shen, Y.-S. Xu, and Z.-Y. Yin, "Analytical approach for time-dependent groundwater inflow into shield tunnel face in confined aquifer," International Journal For Numerical and Analytical Methods in Geomechanics, vol. 42, no. 4, pp. 655-673, 2018.

[31] X.-X. Liu, S.-L. Shen, A. Zhou, and Y.-S. Xu, "Evaluation of foam conditioning effect on groundwater inflow at tunnel cutting face," International Journal for Numerical and Analytical Methods in Geomechanics, vol. 43, no. 2, pp. 463-481, 2019. 